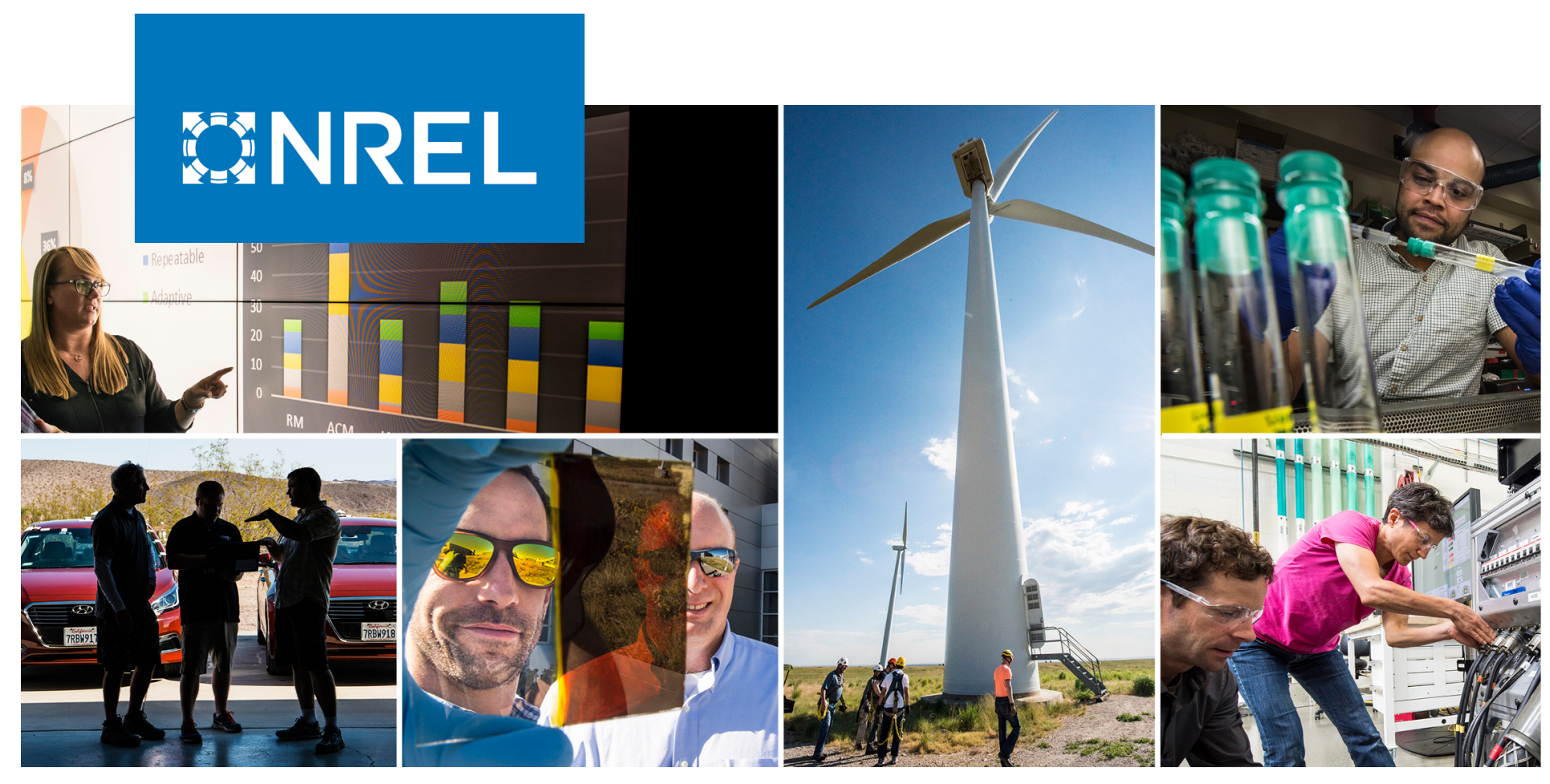

\title{
Representing DC-Coupled PV+Battery Hybrids in a Capacity Expansion Model
}

Kelly Eurek, Caitlin Murphy, Wesley Cole, Will Frazier, Patrick Brown, and Anna Schleifer

NREL is a national laboratory of the U.S. Department of Energy Office of Energy Efficiency \& Renewable Energy

Operated by the Alliance for Sustainable Energy, LLC

This report is available at no cost from the National Renewable Energy Laboratory (NREL) at www.nrel.gov/publications.
Technical Report

NREL/TP-5C00-77917

April 2021 


\title{
FANEL
}

\section{Representing DC-Coupled PV+Battery Hybrids in a Capacity Expansion Model}

\author{
Kelly Eurek, Caitlin Murphy, Wesley Cole, Will Frazier, \\ Patrick Brown, and Anna Schleifer
}

\section{Suggested Citation}

Eurek, Kelly, Caitlin Murphy, Wesley Cole, Will Frazier, Patrick Brown, and Anna Schleifer. 2021. Representing DC-Coupled PV+Battery Hybrids in a Capacity Expansion Model. Golden, CO: National Renewable Energy Laboratory. NREL/TP-5C00-77917. https://www.nrel.gov/docs/fy210sti/77917.pdf.

NREL is a national laboratory of the U.S. Department of Energy Office of Energy Efficiency \& Renewable Energy Operated by the Alliance for Sustainable Energy, LLC

This report is available at no cost from the National Renewable Energy Laboratory (NREL) at www.nrel.gov/publications.

Contract No. DE-AC36-08GO28308
Technical Report NREL/TP-5C00-77917 April 2021

National Renewable Energy Laboratory 15013 Denver West Parkway Golden, CO 80401 303-275-3000 • www.nrel.gov 


\section{NOTICE}

This work was authored by the National Renewable Energy Laboratory, operated by Alliance for Sustainable Energy, LLC, for the U.S. Department of Energy (DOE) under Contract No. DE-AC36-08GO28308. Funding provided by the U.S. Department of Energy Office of Energy Efficiency and Renewable Energy Solar Energy Technologies Office and Strategic Analysis under contract number DE-AC36-08GO28308. The views expressed herein do not necessarily represent the views of the DOE or the U.S. Government.

This report is available at no cost from the National Renewable Energy Laboratory (NREL) at www.nrel.gov/publications.

U.S. Department of Energy (DOE) reports produced after 1991 and a growing number of pre-1991 documents are available free via www.OSTI.gov.

Cover Photos by Dennis Schroeder: (clockwise, left to right) NREL 51934, NREL 45897, NREL 42160, NREL 45891, NREL 48097, NREL 46526.

NREL prints on paper that contains recycled content. 


\section{Acknowledgments}

We gratefully acknowledge the many people whose efforts contributed to this report. Many NREL colleagues reviewed and improved this report, including Paul Denholm, Matt Irish, and Daniel Steinberg. We are also grateful to our external reviewers for providing feedback on this work through an external peer review process, including Zachary Eldredge, Paul Spitsen and Daniel Sodano from the U.S. Department of Energy; Andrew Mills from Lawrence Berkeley National Laboratory; and Cara Marcy from the U.S. Environmental Protection Agency. This work was funded by the U.S. Department of Energy's Office of Energy Efficiency and Renewable Energy - including the Solar Energy Technologies Office and Strategic Analysisunder contract number DE-AC36-08GO28308. All errors and omissions are the sole responsibility of the authors. 


\section{List of Acronyms}

$\begin{array}{ll}\text { AC } & \text { alternating current } \\ \text { BIR } & \text { battery-to-inverter ratio } \\ \text { CEM } & \text { capacity expansion model } \\ \text { DC } & \text { direct current } \\ \text { GIS } & \text { geographic information system } \\ \text { GW } & \text { inverter loading ratio } \\ \text { ILR } & \text { investment tax credit } \\ \text { ITC } & \text { megawatt } \\ \text { MW } & \text { National Renewable Energy Laboratory } \\ \text { NREL } & \text { operations and maintenance } \\ \text { O\&M } & \text { photovoltaic } \\ \text { PV } & \text { Regional Energy Deployment System } \\ \text { ReEDS } & \text { renewable energy certificate } \\ \text { REC } & \text { Renewable Portfolio Standard } \\ \text { RPS } & \text { round trip efficiency } \\ \text { RTE } & \text { System Advisor Model } \\ \text { SAM } & \text { variable renewable energy } \\ \text { VRE } & \end{array}$




\section{Abstract}

Interest in coupled solar photovoltaic (PV) and battery systems has grown due to their ability to receive the federal investment tax credit (ITC) and recent technology cost and performance improvements. Combining these technologies to form co-located or "hybridized" PV+battery systems has the potential to lower costs and increase energy output relative to separate (and similarly sized) PV and battery systems. In this work, we provide an overview of PV+battery systems and demonstrate methods for incorporating them into the National Renewable Energy Laboratory's (NREL's) Regional Energy Deployment System (ReEDS) capacity expansion model. Although the methods are applied to a specific model, we anticipate that the approaches described here can be useful for informing PV+battery method development in other capacity expansion models.

The implemented method leverages the existing representations of independent PV and battery technologies in ReEDS; therefore, the focus of the methodological development is on capturing and parameterizing the interactions between them for a configuration in which the PV and battery technologies share a single bi-directional inverter. This study further explores the impacts of including PV+battery systems in the ReEDS optimization for the conterminous United States through 2050. In particular, we perform a suite of parametric sensitivities for input assumptions that are uncertain and expected to influence PV+battery deployment levels, including the cost of $\mathrm{PV}+$ battery systems relative to independent PV and battery systems; the battery component's qualification for the ITC; and future cost trajectories for PV and battery systems.

From the full set of scenarios, we find that PV+battery deployment could occur throughout the conterminous United States if there are cost savings associated with DC coupling PV and battery technologies (e.g., through shared inverter and balance-of-system costs, reduced financial risk, or increased modularity). Growing PV+battery deployment primarily displaces independent PV and battery technologies, indicating the strong competition between the hybrid and independent configurations comprising technologies with similar performance characteristics. Finally, the total deployment of utility-scale PV+battery hybrids through 2050 intuitively scales with the level of cost savings that can be achieved through hybridization, but it is also highly sensitive to the battery component's ability to realize value from energy arbitrage (based on grid charging). The level of PV+battery deployment is less insensitive to assumptions about the battery component's qualification for the ITC, based on the incentive schedule defined in the December 2020 legislative updates. 


\section{Table of Contents}

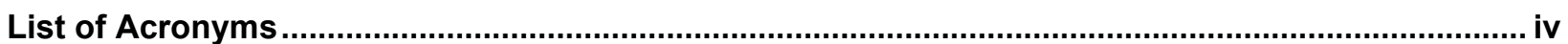

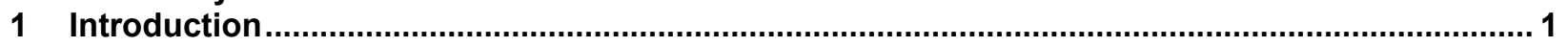

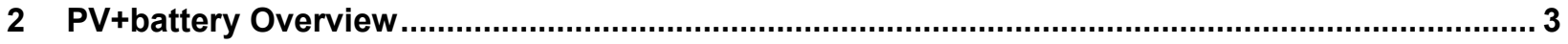

2.1 PV+battery Hybrid Configurations .................................................................................. 3

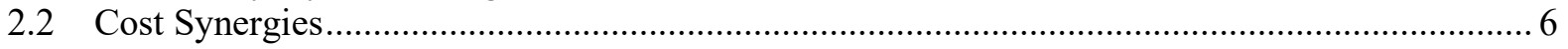

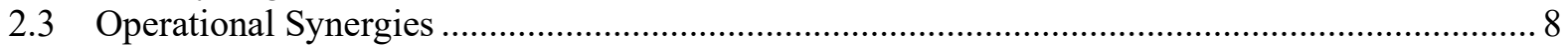

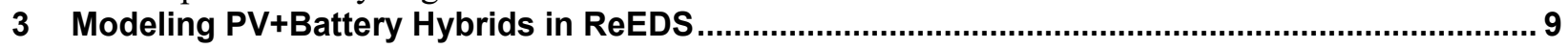

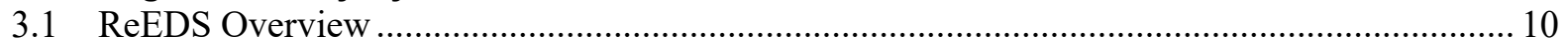

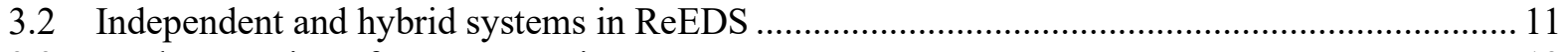

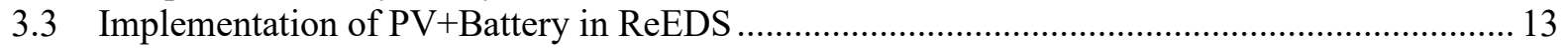

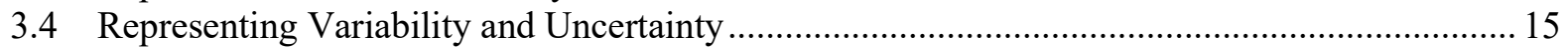

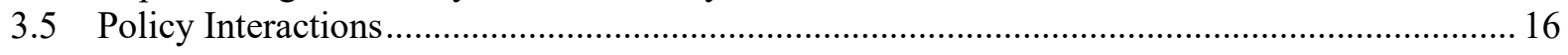

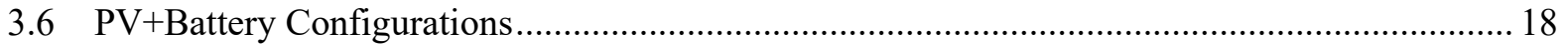

3.7 Tracking Capital Stock with Different Lifetimes .................................................................. 18

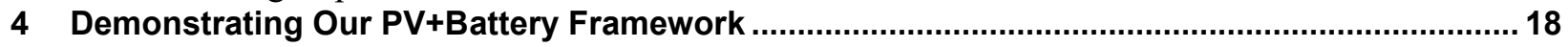

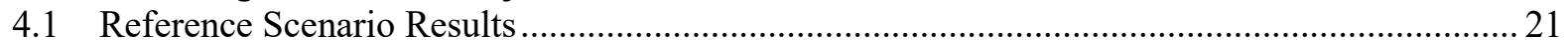

4.2 The Impact of Cost Savings Associated with Hybridization.................................................. 25

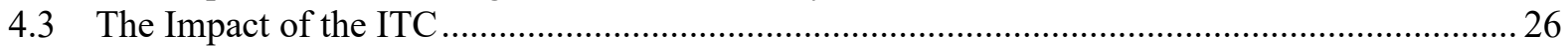

4.4 The Impact of Cost Trajectories for PV and Battery Technologies ......................................... 29

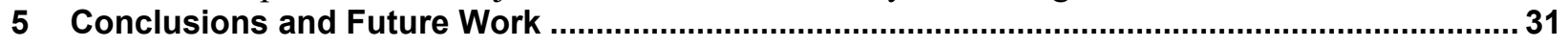

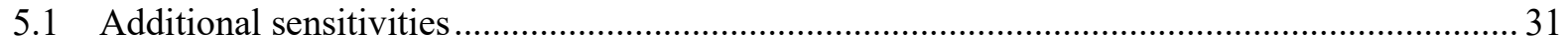

5.2 Improve the representation of the hybrid system's battery component...................................... 32

5.3 Incorporate prescribed PV+battery capacity and near-term future builds................................ 33

5.4 Model the retrofitting of existing PV sites with the addition of a battery …............................... 33

5.5 Incorporate region-specific PV+battery configurations ......................................................... 34

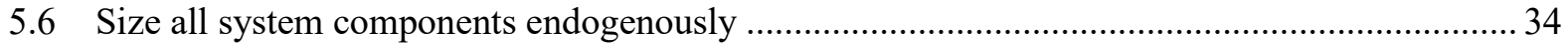

5.7 Evaluate the role of PV+battery in 100\% renewable energy grids .......................................... 34

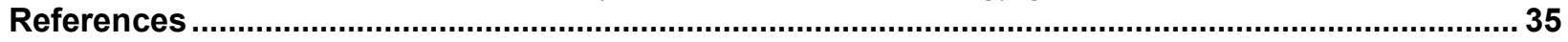




\section{List of Figures}

Figure 1. Online projects that combine utility-scale PV and another generation or energy storage technology at the end of 2019 .

Figure 2. PV+battery plant architectures: (a) loosely DC coupled, (b) tightly DC coupled, and (c) ACcoupled (Denholm, Margolis, and Eichman 2017)............................................................. 5

Figure 3. System costs for various configurations of PV and battery (Fu, Remo, and Margolis 2018b).... 7

Figure 4. In DC-coupled PV+battery systems, this clipped energy can be stored in the battery. For other configurations, the clipped energy would be lost....

Figure 5. Clipping losses associated with 1.3 ILR systems vary by location but are always less than $3 \%$ of

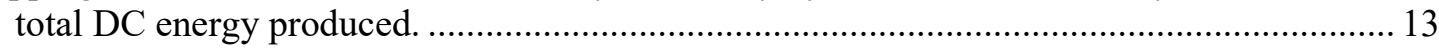

Figure 6. Representation of loosely DC-coupled PV+battery hybrid in ReEDS, including the key investment and operational decision variables.................................................................... 14

Figure 7. Representation of loosely DC-coupled hybrid PV+battery in ReEDS, including the key operational constraints.

Figure 8. Evolution of utility-scale PV capacity in the "No Hybrids" and Reference scenarios.

Figure 9. Regional deployment of PV+battery hybrids in the Reference case, where capacity is reported as the PV array capacity in $\mathrm{GW}_{\mathrm{AC}}$.

Figure 10. Capacity differences between the Reference and "No Hybrids" scenarios............................. 23

Figure 11. Utilization of the PV+battery hybrid components by ReEDS time-slice for all PV+battery

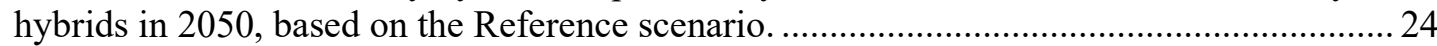

Figure 12. Installed UPV (left) and battery (right) capacity by 2050 for hybrid and independent systems across sensitivities related to the capital cost impacts of hybridization..................................2 26

Figure 13. Number of PV+battery systems whose dispatch characteristics do not meet the ITC requirement in the first year of operation (2020-2050) under the Reference Scenario.......... 28

Figure 14. Installed UPV (top) and battery (bottom) capacities in 2050 for hybrid and independent systems across different levels of cost savings combined with varying assumptions for future

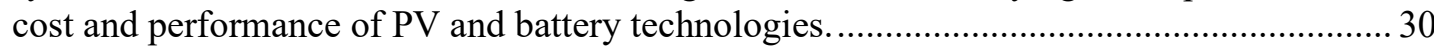

Figure 15. Installed UPV (left) and battery (right) capacity by 2050 for hybrid and independent systems across sensitivities related to the ITC charging requirement.

Figure 16. Share of PV+battery systems whose battery components qualify for the partial ITC value $(75 \%)$, based on the first year of operation.

Figure 17. Installed UPV (left) and battery (right) capacity in 2050 for hybrid and independent systems across sensitivities related the hourly energy arbitrage value.

\section{List of Tables}

Table 1. Model parameters for independent and DC-coupled PV and battery technologies.................... 12

Table 2. Key assumptions that define the scenarios and insights in this section. .....................................2 20

Table 3. Variables for representing a loosely DC-coupled PV+battery technology in ReEDS................. 40 


\section{Introduction}

Deployment of solar photovoltaic (PV) and battery technologies is growing rapidly within the U.S. bulk power system. Over $8 \mathrm{GW}$ DC of utility-scale PV capacity and $523 \mathrm{MW}$ of front-of-themeter energy storage were deployed in 2019. This utility-scale energy storage was added to provide a variety of services, such as peak shaving, frequency regulation, arbitrage, load management, and avoided curtailment. Deployment rates for both technologies also appear to be accelerating: utility-scale PV installations were $89 \%$ greater in the first half of $2020^{1}$ than they were in the first half of 2019 , and the procurement of nearly $1.2 \mathrm{GW}$ of energy storage to be installed in 2021 has been announced in California alone (Feldman and Margolis 2020).

Recent and expected PV and battery deployments in the United States reflect a combination of technology cost and performance improvements (Jones-Albertus et al. 2018; Bolinger, Seel, and Robson 2019; Cole and Frazier 2020; NREL 2020) and policy drivers (Barbose 2019). With this growing deployment comes challenges in terms of both their integration and the declining marginal value of additional PV for energy, capacity, and ancillary services (Mills and Wiser 2012; Hirth 2013; 2015; Cole, Frew, et al. 2018; Bolinger, Seel, and Robson 2019). Moreover, the broader increase in penetration of variable renewable energy (VRE) technologies has led to a growing demand for firm capacity and flexibility (Denholm et al. 2016; English et al. 2020).

Under current conditions, the coordinated investment in and operation of complementary components - through PV+battery systems - is seen as one strategy for mitigating integration challenges and providing additional opportunities for system benefits. Growing interest in $\mathrm{PV}+$ battery systems is apparent in the large volume of relevant academic and industry studies, and it can also be observed in recent installations (Figure 1), the immediate project pipeline, and interconnection queues (Gorman et al. 2020; Hledik et al. 2019; Gramlich, Goggin, and Burwen 2019; Bolinger, Seel, and Robson 2019; Feldman, Zwerling, and Margolis 2019). For example, the U.S. Energy Information Administration reports that $14 \%$ of all PV systems proposed to be built from 2020 through 2023 will be paired with energy storage. ${ }^{2}$

Within the context of industry interest in PV+battery systems, there is a growing need to determine their future market potential, which will depend on both their cost and value. $\mathrm{PV}+$ battery costs have been explored through bottom-up cost modeling ( $\mathrm{Fu}$, Remo, and Margolis 2018b) and reported power purchase agreement prices for select configurations (Bolinger, Seel, and Robson 2019). PV+battery value is most-often evaluated via site-level or project-level energy analysis based on price-taker analysis that maximizes revenue for the plant owner (Denholm, Margolis, and Eichman 2017; Gorman et al. 2020; DiOrio, Denholm, and Hobbs 2020; Schleifer et al. 2021).

\footnotetext{
${ }^{1}$ More than $7 \mathrm{GW}_{\mathrm{DC}}$ of PV capacity was installed in the first half of 2020 alone, over half of which occurred in California, Texas, and Florida (Feldman and Margolis 2020).

${ }^{2}$ Based on the 2019 early release of form EIA-860 (https://www.eia.gov/electricity/data/eia860/), another 4.1 GW of utility-scale PV is proposed to be built, paired with $1.5 \mathrm{GW}$ of battery storage, from 2020 through 2023. For comparison, $581 \mathrm{MW}$ of U.S. utility-scale PV systems were built, paired with $138 \mathrm{MW}$ of storage (387 MWh), between 2015 and 2019. This represents approximately 2\% of U.S. utility-scale PV system capacity and 16\% of utility-scale battery system capacity (MW) installed during that time (Feldman and Margolis 2020).
} 


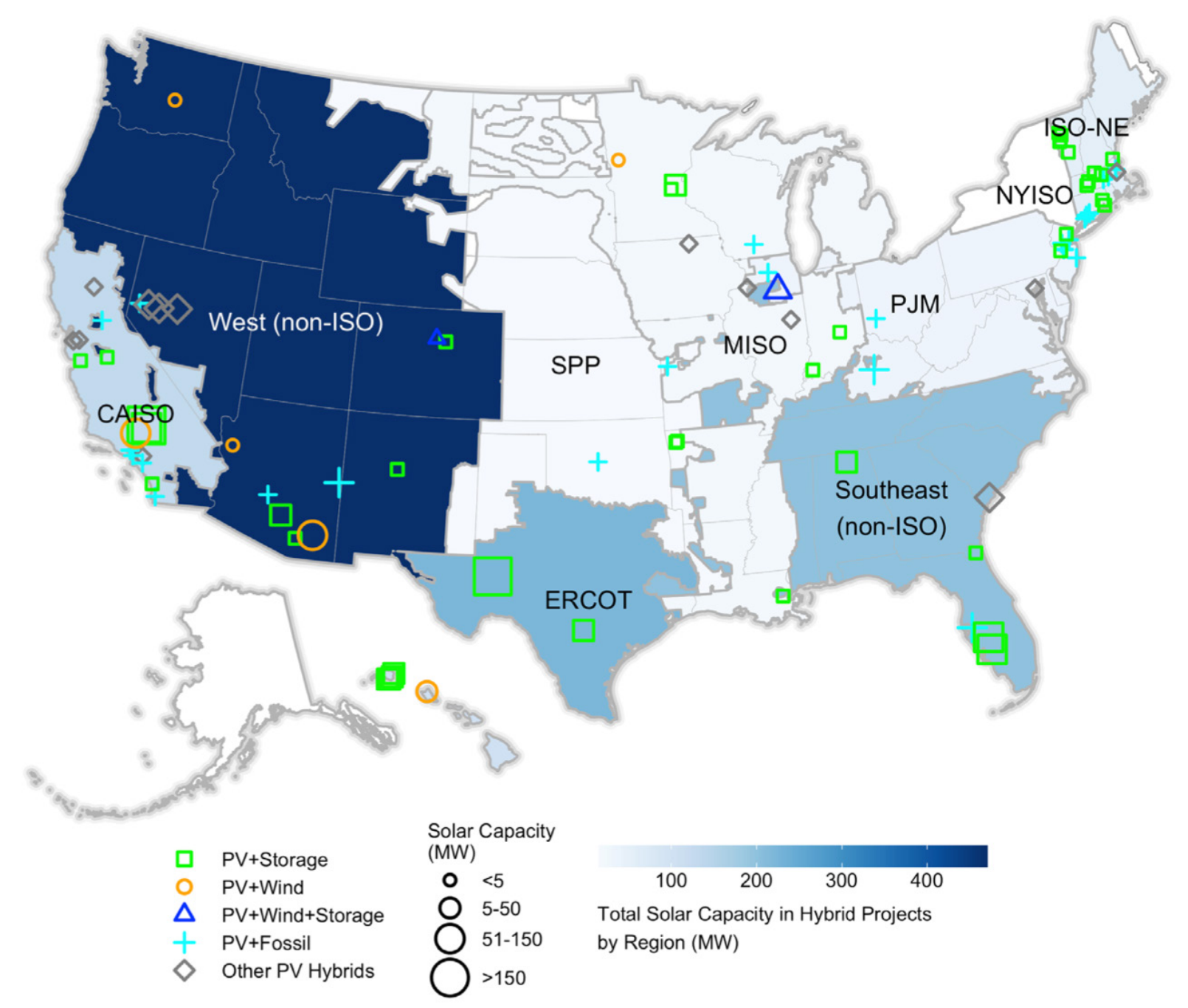

Figure 1. Online projects that combine utility-scale PV and another generation or energy storage technology at the end of 2019.

Green squares indicate PV+battery deployments, where the size of the square scales with the solar capacity.

Reproduced from (Wiser et al. 2020). Used with permission.

Limited examples exist within the literature of analyses exploring the future techno-economic potential of utility-scale PV+battery systems based on capacity expansion modeling, the type of modeling used in this study and in utilities' integrated resource planning. A capacity expansion model (CEM) optimizes future investments in generation assets and transmission infrastructure at regional to international scales, subject to the physical constraints of the power system, future technology cost estimates, policy constraints, and reliability constraints (e.g., meeting load, provisioning operating reserves, and meeting planning reserve margin requirements). Multiple CEM studies demonstrate deployment of utility-scale PV and battery technologies as independent systems that interact with each other, such that interaction is beneficial for the entire grid (Cole, Frew, et al. 2018; Sepulveda et al. 2018; Bistline and Young 2019; Fälth et al. 2020). Only a few recent CEM efforts have included PV+battery systems ( Cowiestoll 2020; US EIA 2021), which are often represented in a way that prohibits charging from the grid. 
In this paper, we summarize the characteristics that make PV+battery systems distinct from their independent PV and battery counterparts (Section 2), which informed our development of a new PV+battery technology in a long-term CEM (Section 3). We then demonstrate how this new capability influences future electric sector scenarios under a range of assumptions for impactful $\mathrm{PV}+$ battery cost parameters (Section 4). This work is intended to help electricity system modelers in thinking about how to represent PV+battery technologies in CEMs, and its contributions to the literature include:

- A U.S. capacity expansion model of DC-coupled PV+battery power plants;

- A geographically-resolved model of deployment potential for PV+battery power plants across the conterminous United States into the future;

- Discussion of which aspects of renewable energy-plus-storage plants can and should be captured in long-term planning models;

- A summary of lessons learned and observations for other modelers attempting to represent renewable energy-plus-storage plants in large-scale grid models; and

- Insights from demonstrations of the new modeling capability.

\section{PV+battery Overview}

PV+battery systems are designed to realize net economic benefits through co-locating and/or jointly scheduling the component technologies (C. A. Murphy, Schleifer, and Eurek 2021). $\mathrm{PV}+$ battery systems that are co-located but operated in a largely independent fashion are typically classified as co-located resources; such a setup has more limited opportunities for incremental value, but it may benefit from cost savings and/or a faster interconnection process.

Multiple industry definitions consider the co-location of assets to be a necessary but insufficient criterion for achieving the "hybrid resource" classification (Gramlich, Goggin, and Burwen 2019; Ahlstrom et al. 2019; California ISO 2019; MISO Energy Storage Task Force 2019). These entities further called for the requirement of an operational linkage, in the form of a single control system, a single market resource identifier, and joint bids and dispatch signals (California ISO 2019; Ahlstrom et al. 2019; Gramlich, Goggin, and Burwen 2019). These PV+battery hybrid configurations are the focus of this study, and they can take many forms.

\subsection{PV+battery Hybrid Configurations}

$\mathrm{PV}+$ battery configurations are defined by the sizing of components and the nature of coupling between them. The components that make up a PV+battery hybrid are similar to those involved in corresponding independent systems. PV panel arrays collect solar energy and generate direct current (DC) power, which is converted to alternating current (AC) via an inverter at the interface with the grid. The ratio of the PV array capacity $\left(\mathrm{MW}_{\mathrm{DC}}\right)$ to the inverter capacity $\left(\mathrm{MW}_{\mathrm{AC}}\right)$ is known as the inverter loading ratio (ILR), or DC-to-AC ratio. In 2018, the median ILR for both tracking and fixed-tilt PV projects was slightly above 1.3, which allows the inverters to operate close to (or at) full capacity for more of the day, relative to an ILR of 1.0 (Bolinger, Seel, and Robson 2019). 
Battery systems convert DC power into stored chemical potential energy, such that an independent battery project involves a bidirectional inverter ${ }^{3}$ that facilitates charging from, and discharging onto, the grid. Battery sizes are defined by both a power rating (in MW) and a duration (in hours), the combination of which provides the energy rating (in MWh). An important performance parameter for battery systems is the roundtrip efficiency (RTE), which is defined as the energy provided by the battery divided by the energy needed to charge the battery.

The PV+battery architecture represents the nature of coupling, which defines whether the PV and battery components are coupled on the grid side of the inverter (AC-coupled) or the plant side of the inverter (DC-coupled) (Figure 2). In an AC-coupled PV+battery system, the PV and battery systems are connected to the same AC bus and access the same transmission line, but they are operated through separate inverters. ${ }^{4}$ As a result, multiple conversion steps are needed to charge the battery from the coupled PV, and each technology is subject to its individual inverter limit; on the other hand, both technologies can be dispatched simultaneously such that the total energy output and capacity credit are based on the sum of the separate inverters (up to the interconnection limit). AC-coupled PV+battery systems can be classified as hybrids if their components are operated in a coordinated fashion, resulting in a single bid and dispatch.

In a DC-coupled system, the PV and battery components share a single inverter, and energy used to charge the battery passes through a DC-to-DC converter. In such an architecture, the hardware and controls can either allow charging the battery from the grid (in a loosely-coupled architecture) or disallow it (in a tightly-coupled architecture; see Figure 2). In both cases, excess PV generation that exceeds the inverter capacity limit (and is therefore "clipped" by the inverter) can be sent to the battery instead. However, the former requires a bi-directional inverter whereas the latter can utilize a standard PV inverter, both of which must be augmented with a DC-to-DC converter to facilitate charging from the local PV.

Loosely DC-coupled systems are the focus of this paper because they require new modeling methods and inputs (see Section 3) and have characteristics that make them distinct from separate PV and battery plants. In particular, loosely DC-coupled PV+battery systems introduce operational synergies that increase their value proposition by enabling higher efficiencies and the recovery of PV generation that cannot be utilized in the absence of a DC-coupled battery. Similar characteristics are not shared by the other PV+battery architectures:

- The model used in this study cannot meaningfully differentiate the operations of an ACcoupled PV+battery hybrid from those of independent PV and battery systems, because the technologies are geographically indistinct within a given balancing area. Therefore, AC-coupled PV+battery systems would only be distinct from separate systems in ReEDS through the combined investment decision, which would require the technologies to be deployed in the same location, at the same time, and potentially at a lower cost. ${ }^{5}$

\footnotetext{
${ }^{3}$ Due to their bi-directional nature, the power electronics interface between a battery and the grid can more accurately be referred to as a bi-directional converter.

${ }^{4}$ In an AC-coupled system, the PV component is operated through a PV inverter and the battery component is operated through a bi-directional inverter, the latter of which can allow for charging from the grid.

${ }^{5}$ It is challenging to further differentiate between AC-coupled and independent systems in ReEDS because individual AC buses are not represented.
} 
- Tightly DC-coupled PV+battery systems can be modeled in the same way as concentrating solar power plants with thermal energy storage (C. Murphy et al. 2019). Therefore, evaluating tightly DC-coupled PV+battery systems could be accomplished with the existing model architecture (with updated cost and performance characteristics).

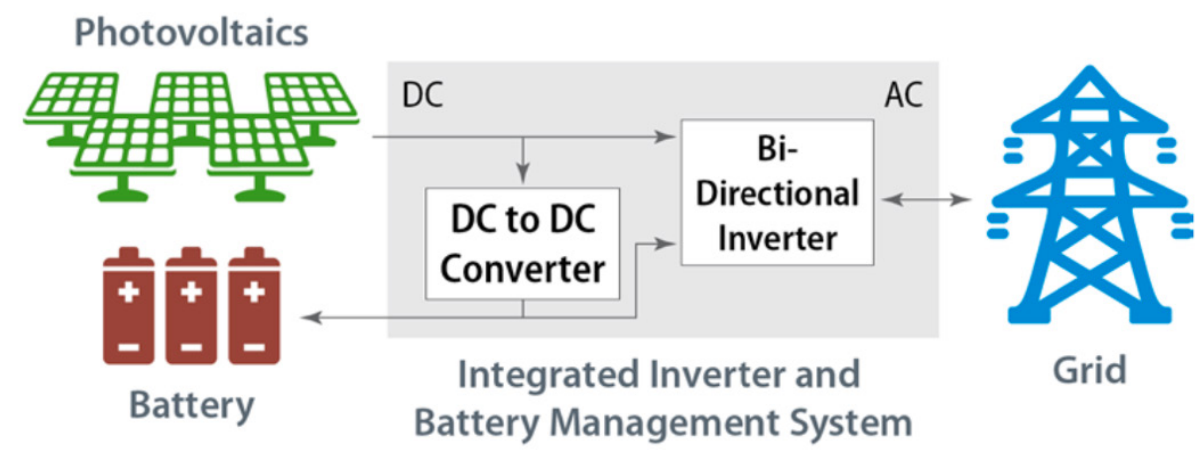

(a) DC-coupled (flexible charging)
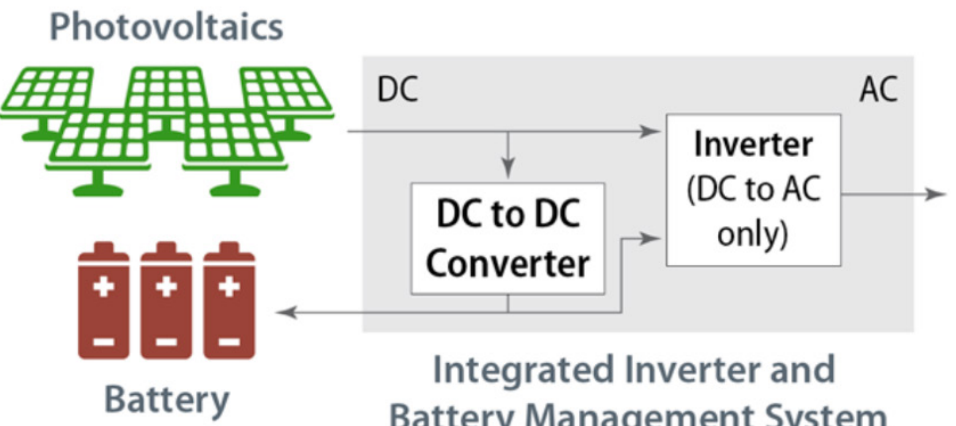

Integrated Inverter and

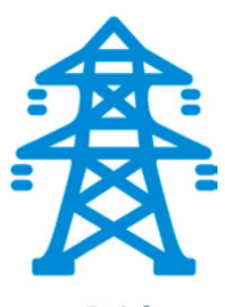

Battery

Battery Management System

(b) DC tightly coupled (PV-only charging)

\section{Photovoltaics}
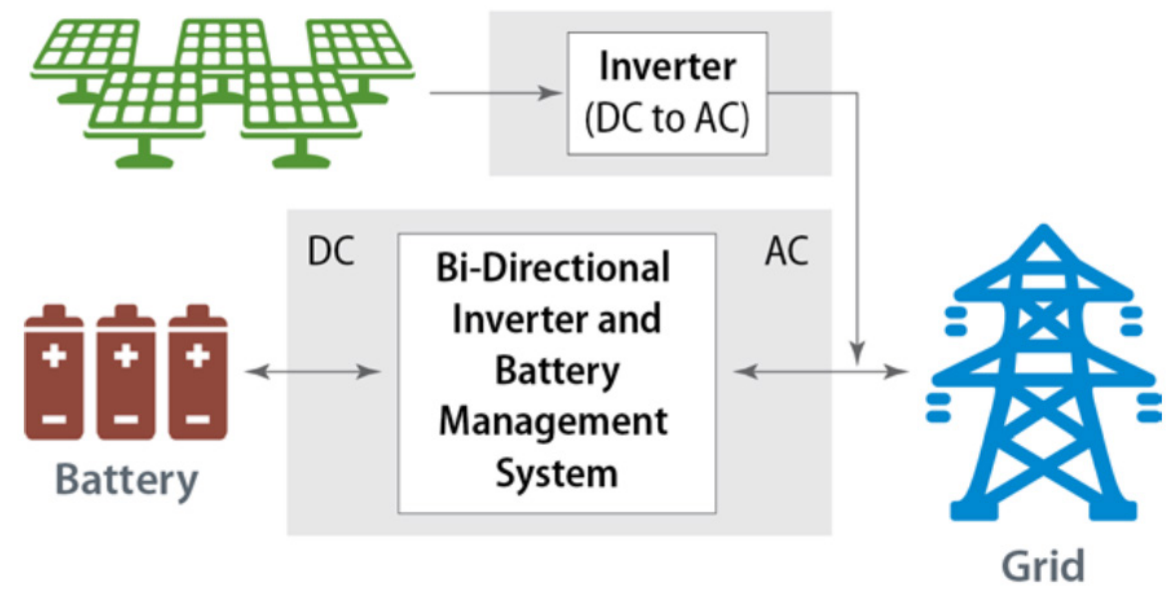

(c) AC coupled

Figure 2. PV+battery plant architectures: (a) loosely DC coupled, (b) tightly DC coupled, and (c) AC-coupled (Denholm, Margolis, and Eichman 2017). 


\subsection{Cost Synergies}

Bottom-up cost models estimate the potential for cost savings associated with the full range of $\mathrm{PV}+$ battery configurations. These models estimate costs related to engineering, procurement, and construction (EPC) and project-development functions, and they often include a detailed treatment of balance-of-system (BOS) $\operatorname{costs}^{6}$ (Fu, Remo, and Margolis 2018a; 2018b; Eberle et al. 2019). The underlying data and relevant bottom-up cost models are rooted in readily available information for independent PV and battery systems (Fu et al. 2015; Fu, Remo, and Margolis 2018a; Bolinger, Seel, and Robson 2019; NREL 2020). However, carefully crafted scenario definitions are needed to represent the potential for shared costs in PV+battery systems.

Cost synergies in PV+battery systems are associated with shared infrastructure, shared BOS costs, financial incentives for hedging against wholesale risk, and the federal investment tax credit (for qualifying projects). PV+battery systems can share hardware that serves both the PV and battery technologies, such as the medium-voltage transformer and switchgear. In addition, all forms of coupling can share soft costs for categories that are applied per project (rather than as a function of project size), with the most impactful being the shared transmission interconnection (Fu, Remo, and Margolis 2018b; 2018a; Ericson et al. 2017).

In DC-coupled systems, additional cost savings can be achieved through the use of a single inverter, which is shared between the PV and battery components. Levelized costs (e.g., costsper-MW or costs-per-MWh) would also be influenced by the selected ILR, because DC-coupled systems can accommodate significantly oversized PV arrays (i.e., higher ILRs) without inducing clipped or otherwise spilled energy. How the PV+battery plant costs vary as a function of ILR would depend primarily on the PV panel costs, whose relative share of total plant costs have been declining over time.

On the other hand, one must account for the related increases in costs associated with DC coupling, such as the (a) need for DC-to-DC converters, (b) more sophisticated control systems to co-optimize the utilization of both the PV and battery components, and (c) more complex and integrated design, which would likely lead to higher structural BOS, electrical BOS, and labor costs. The operations and maintenance (O\&M) costs associated with DC-coupled systems may also be higher than those for two independent or AC-coupled systems; in particular, DC coupling is typically implemented by locating the batteries next to the PV arrays (rather than on the outskirts of the PV field), which could lead to additional O\&M costs due to maintenance crews having to enter and service batteries throughout the PV field (Fu, Remo, and Margolis 2018b).

Considering all of these cost categories and dynamics together, it is difficult to know a priori whether the net effect of hybridization results in cost savings or cost increases, and whether it depends on the nature of coupling. Estimates in the literature for the relative costs of PV+battery, $\mathrm{PV}$, and battery systems are sparse and have been reported for only select configurations. General trends indicate that both AC-coupled and DC-coupled systems have lower costs than their independent counterparts (i.e., separate PV and battery projects). These estimates do not

\footnotetext{
${ }^{6} \mathrm{BOS}$ costs include all costs besides those for the PV panels and battery packs, including all hardware, software, labor, permitting, overhead, and financials associated with enabling the movement of the energy produced (and stored) through the conversion system and onto the grid.
} 
capture all potential sources of cost savings (e.g., reduced financial risk and increased modularity), and they can also be challenging to interpret. For example, Fu et al. (2018b) present PV+battery costs based on a constant DC capacity rating (e.g., PV panels or array size; Figure 3), which means both the costs and values will differ between the independent and hybrid systems considered. However, their findings are often used to support statements about the cost savings associated with hybridization more generally (Hledik et al. 2019; Gramlich, Goggin, and Burwen 2019), which cannot be decoupled from corresponding changes in value (Gorman et al. 2020;

DiOrio, Denholm, and Hobbs 2020; Schleifer et al. 2021).

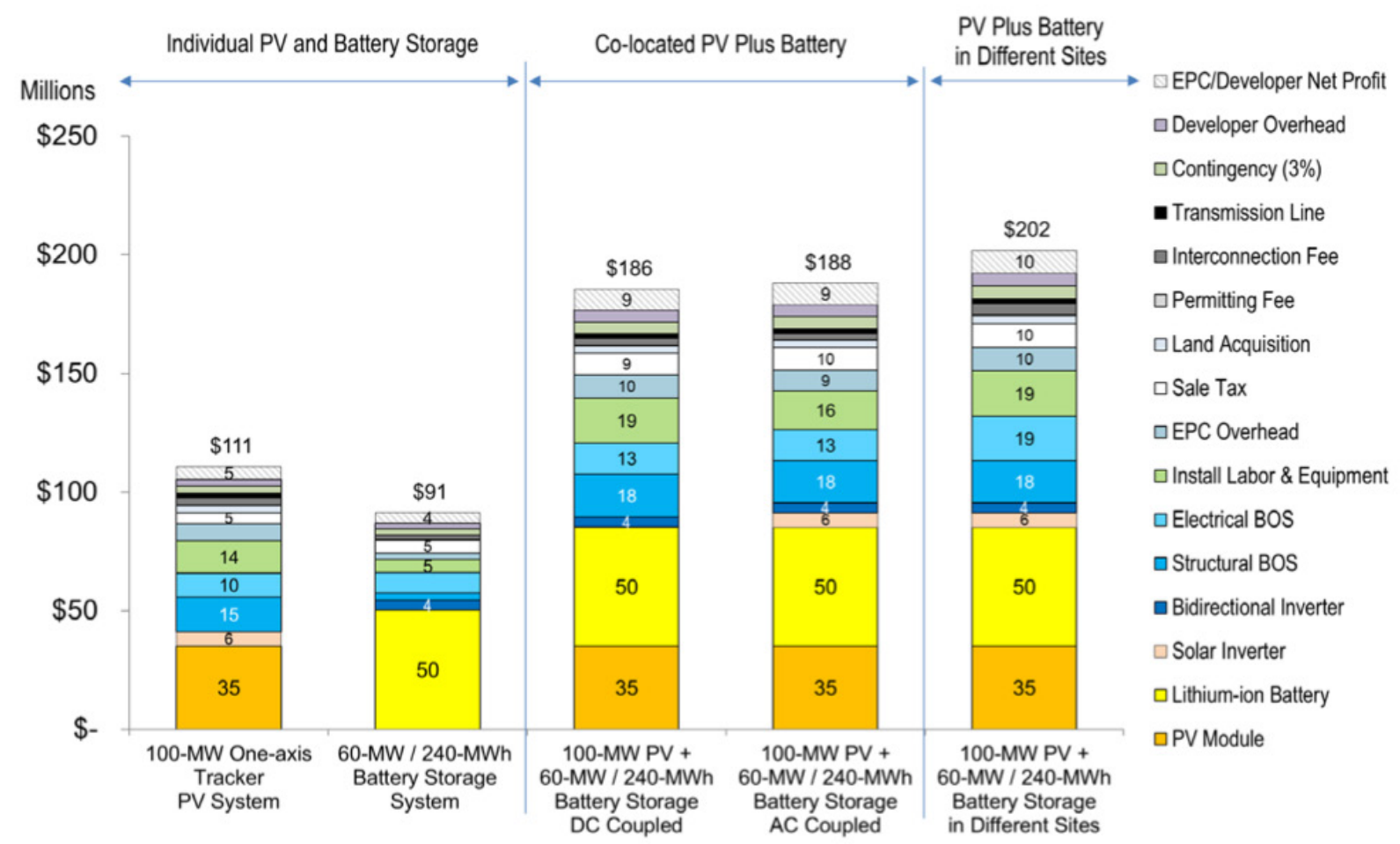

Figure 3. System costs for various configurations of PV and battery (Fu, Remo, and Margolis 2018b).

Determining the cost-optimal design of a PV+battery system further requires considering these configuration-dependent costs on a life-cycle basis, which accounts for equipment replacement costs that depend on how the plant will be operated; technology costs as a function of time; the probability of component failures over time (NREL et al. 2018); and policy drivers. Of particular importance is representing the relationships between battery operation and degradation, which are inherent in any battery project but also depend on the nature of coupling; in other words, the lifetime of a battery would differ in independent and hybrid deployments if the latter drives a change in cycling to maximize revenue. Moreover, determining the lifecycle costs requires consideration of how the technology costs change over time, since replacement costs in the future will likely be lower than capital costs today (Cole and Frazier 2020; NREL 2020; Jean, Woodhouse, and Bulović 2019). 
Finally, the total cost of a PV+battery hybrid depends on the federal investment tax credit (ITC), which can be applied to both PV and battery expenses for qualifying projects (DOE 2020). ${ }^{7}$ Offsetting the battery costs in a PV+battery hybrid via the ITC requires meeting eligibility criteria, including a minimum amount of charging from, proximity to, and common ownership with a qualifying renewable energy system. Moreover, the level of incentive for the battery component scales with how much of the stored energy is derived from the PV to which it is coupled (Gramlich, Goggin, and Burwen 2019; Elgqvist, Anderson, and Settle 2018).

\subsection{Operational Synergies}

$\mathrm{PV}+$ battery systems also have the potential to realize value synergies. Some of the potential synergies are not specific to hybrids and instead reflect well-established interactions between PV and battery systems in general (Denholm and Mai 2019). For example, both separate and coupled PV and battery systems can avoid low or negative price regimes (during periods of high VRE production and/or transmission congestion) by sending PV generation to storage during those time periods. Such a strategy further reduces the effective charging cost, since energy purchased from the grid would have a higher cost. Similarly, both separate and coupled battery systems can provide spinning reserves and contribute to ramp control.

Coupling with a PV system may make it more cost-effective for the battery component to receive a full capacity credit in regions where it would be cost prohibitive for batteries on their own (Frazier et al. 2020). However, such interactive effects must be considered within the context of limitations imposed by the shared inverter in a DC-coupled PV+battery hybrid. For tightly DCcoupled systems in particular, the capacity credit may be reduced if the solar array is not generating enough to recharge the storage device between high-risk periods (from a resource adequacy perspective) (Schleifer et al. 2021). The capacity credit of a loosely DC-coupled system may be somewhat larger (but still smaller than the sum of the capacity credits for independent PV and battery systems), especially in regions with longer-duration high-risk periods (Mills and Rodriguez 2019; Cowiestoll 2020).

Operational synergies that are unique to DC-coupled systems include the abilities for avoided clipping and low-voltage harvesting. Avoided clipping refers to the fact that the sharing of an inverter allows DC-coupled systems to send PV generation that would otherwise be clipped by the inverter (based on the inverter capacity) directly to the coupled battery storage device. This incremental "energy harvesting" (Figure 4) is one of the reasons why it is expected that DCcoupled PV+battery systems will eventually involve relatively large ILRs, since the otherwiseclipped energy can be put to use at a later point in the day. Moreover, it may be especially valuable in regions with aggressive renewable portfolio standards - and related solar carveouts, storage carveouts, and storage mandates - which provide an incentive for the recovery and utilization of otherwise curtailed PV generation (Gorman et al. 2020; Ahlstrom et al. 2019;

\footnotetext{
${ }^{7}$ The value of the ITC is based on existing statutes and guidance from the U.S. Internal Revenue Service, which define commence construction and construction timeline requirements. The ITC can offset up to $30 \%$ of eligible expenses associated with qualifying projects that commence construction before $2020 ; 26 \%$ for projects that commence construction in $2020-2022 ; 22 \%$ for projects that commence construction in 2023 ; and $10 \%$ for projects that commence construction after 2023 or are brought online after 2025.
} 
DiOrio, Denholm, and Hobbs 2020; Denholm, Margolis, and Eichman 2017; Hledik et al. 2019; Mai et al. 2021).

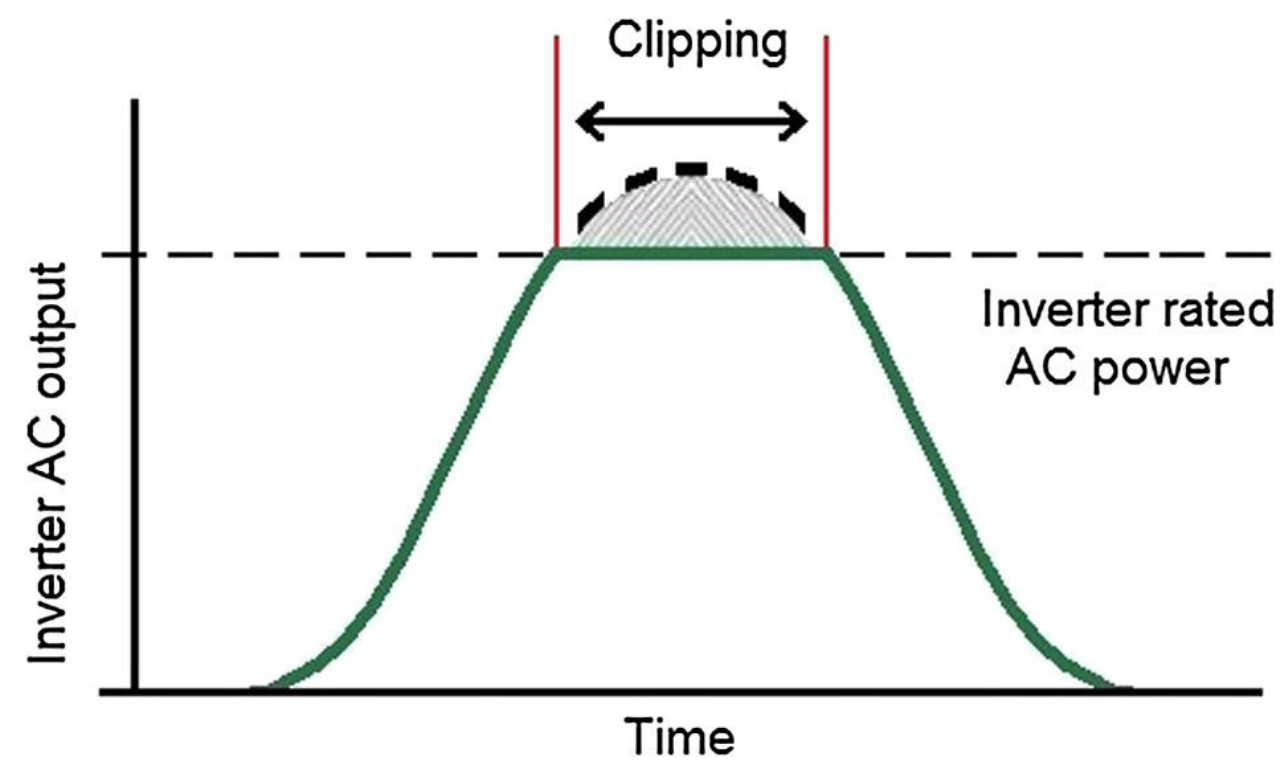

Figure 4. In DC-coupled PV+battery systems, this clipped energy can be stored in the battery. For other configurations, the clipped energy would be lost.

Reproduced from Serdio Fernández, Muñoz-García, and Saminger-Platz (2016). Used with permission.

An additional (and likely smaller-magnitude) source of value synergy for DC-coupled systems is low-voltage harvesting (not modeled here); this refers to the fact that some solar energy is collected at voltages that are below the minimum rating for the inverter (e.g., during sunrise, sunset, and very cloudy periods). Moreover, a tightly DC-coupled architecture may simplify (and therefore accelerate) the interconnection process for the battery component, because the joint system will only act as a power source and never as a load (FERC 2020).

Despite these potential benefits of PV+battery hybrids, there are also limitations. The components must be co-located to be able to share equipment or infrastructure, which might limit value opportunities if one of them is sited in a sub-optimal location. Moreover, coupling a battery to a generator behind the inverter limits the discharge from the battery during hours of high $\mathrm{PV}$ production. If that also coincides with times of high demand or high prices, then sharing a single inverter could limit the value that can be provided by a DC-coupled system relative to other configurations. Finally, a system operator may have concerns about the transmission congestion and reliability implications of a loosely DC-coupled system, especially if the operator does not have visibility into the status and control of the PV and battery components.

\section{Modeling PV+Battery Hybrids in ReEDS}

In this section, we describe the methods for representing the cost and value synergies of $\mathrm{PV}+$ battery in a capacity expansion model (CEM) for the U.S. electric power system, vis-à-vis the characteristics of independent PV and battery technologies. In particular, we describe our approach to modifying the 2020 version of NREL's Regional Energy Deployment System (ReEDS) model to represent loosely DC-coupled PV+battery hybrids. The present representation captures multiple benefits of hybridization (including cost savings and operational synergies), 
parameterizes cost and performance characteristics for PV+battery hybrids, and constrains the system design and operation to represent the shared inverter.

\subsection{ReEDS Overview}

ReEDS is a national-scale capacity expansion model that optimizes deployment and operation of bulk power system assets through 2050 (Brown et al. 2020). It is primarily applied to the conterminous U.S. power system, but versions of the model also exist for India (Rose et al. 2020), Canada (Martinez et al. 2013), and Mexico (Ho, Cole, and Spyrou 2017). ReEDS takes a central decision-making approach that minimizes total system cost subject to meeting physical and policy constraints. It simultaneously considers generation, storage, and transmission when making system buildout and operational decisions.

The ReEDS model includes high spatial resolution, which is defined by 134 modeled balancing areas and 356 renewable energy resource regions. These modeled balancing areas can be aggregated up to state and regional transmission organization footprints, which are used to specify local constraints and requirements (e.g., state-level policies and operating reserve constraints). In addition, the trading of energy and capacity services between modeled balancing areas is facilitated by inter-regional transmission lines. This spatial resolution enables ReEDS to represent the dispersed and location-restricted characteristics of renewable energy technologies.

The high spatial resolution is one of many features that demonstrate how ReEDS has been designed with an emphasis on capturing the challenges of and opportunities for integrating renewable energy resources onto the bulk power system. The model includes resource supply curves for renewable energy resources, which limit the amount of capacity that can be built in each region and captures the cost of connecting remote resources to existing transmission capacity. ReEDS further represents VRE curtailment, the contribution of VRE to net peak load requirements, and the need to hold additional operating reserves as VRE penetration grows.

ReEDS is temporally resolved into 17 time-slices that are blocks of non-chronological aggregate hours for one representative day within each of the four seasons. Each day is composed of four time-slices, including morning, afternoon, evening, and night. Additionally, one peak time-slice represents the highest 40 hours of load during the year. For each solution interval from 2010 to 2050, ReEDS dispatches all generation and storage in each of these 17 time-slices to capture seasonal and diurnal electricity load and renewable generation profiles.

By default, ReEDS is solved sequentially, meaning that investment decisions are made in a given year based on limited information about the future. This information is updated as the model steps forward in time and new investment decisions are made. With this approach, future decisions are dependent upon decisions made in prior years, thus creating a "path dependency" effect. Therefore, long-term model outcomes should be interpreted based on the path that the model has taken since the starting point.

ReEDS has been employed for a wide range of analyses, ${ }^{8}$ including many that have focused on the interactions of PV and storage as independent systems (Cole, Frew, et al. 2018; Frazier et al.

\footnotetext{
${ }^{8}$ See https://www.nrel.gov/analysis/reeds/publications.html.
} 
2020; Cole, Greer, et al. 2020). As of 2019, open access to the model is available to the public. ${ }^{9}$ For more details about the ReEDS model, see the model documentation (Brown et al. 2020).

\subsection{Independent and hybrid systems in ReEDS}

Table 1 summarizes the values used in ReEDS to represent independent and hybrid versions of $\mathrm{PV}$ and battery technologies. The final column represents the parameterization of $\mathrm{PV}+$ battery hybrids for initial testing in the ReEDS model, and it does not necessarily indicate the full range of systems that should be considered.

Battery parameters are largely the same between independent and hybrid configurations, except that coupling leads to (a) the potential for lower battery costs, (b) the battery's ability to qualify for the ITC, and (c) a capacity credit that is limited by the shared inverter's capacity. There are many other performance parameters not included in Table 1 that remain unchanged between the independent and hybrid technologies, including technical potential, transmission spur line costs, fixed and variable O\&M costs, degradation rates, forced and planned outage rates, and the hourly arbitrage value of storage. The latter parameter is particularly important to note, because it represents a significant source of value for independent battery technologies in ReEDS; because the battery component of a coupled system may realize less arbitrage value than an independent battery (due to the shared inverter), we plan to update this representation in the future to derate (and avoid overestimating) the arbitrage value for the hybrid system.

Independent PV capacity factors ${ }^{10}$ for ReEDS are calculated based on the AC output from the inverter, so they account for clipping losses, low voltage losses, and inverter losses. For $\mathrm{PV}+$ battery systems, ReEDS needs information about the additional energy potential that could be recovered in a hybrid configuration but would be wasted for independent PV. The relative magnitude of clipped energy increases as the ILR increases, and it has the potential to occur during all daylight time-slices in ReEDS: morning (6am-1pm), afternoon (1pm-5pm), and evening (5pm-10pm, to a lesser extent). For a single-axis tracking system with an ILR of 1.3, we assume clipping losses are $0.2 \%$ of DC energy. This value is based on estimates of DC power and AC power from simulations using NREL's System Advisor Model (SAM) with seven years (2007-2013) of hourly solar resource data at over 55,000 sites across the United States (Figure 5. and Appendix B). Therefore, we increase the AC capacity factors of PV by $0.2 \%$ in the daylight time-slices to represent clipped energy that can be recovered through DC-coupled storage, accounting for the battery-related losses associated with storing that recovered generation. These capacity factors are assumed to degrade at the same rate as standalone PV systems (0.7\%/year).

\footnotetext{
${ }^{9}$ See https://www.nrel.gov/analysis/reeds/request-access.html.

10 Traditionally, the PV variables and parameters used in ReEDS are defined relative to the array capacity (MW $\mathrm{DC}_{\mathrm{DC}}$.

The capacity factor used in ReEDS is, therefore, expressed as $\mathrm{MW}_{\mathrm{AC}}$ output divided by $\mathrm{MW}_{\mathrm{DC}}$ capacity.
} 
Table 1. Model parameters for independent and DC-coupled PV and battery technologies.

\begin{tabular}{|c|c|c|c|}
\hline & Independent Systems & \multirow{2}{*}{$\begin{array}{l}\text { Loosely DC-Coupled } \\
\text { Cost savings or increases are applied as a } \\
\text { percentage change relative to the sum of } \\
\text { independent systems' costs }\end{array}$} \\
\hline 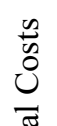 & PV & $\begin{array}{l}\text { Values from the } 2020 \text { Annual Technology } \\
\text { Baseline (NREL 2020) }\end{array}$ & \\
\hline שี & Storage & $\begin{array}{l}\text { Function of duration based on Cole and } \\
\text { Frazier (2020) }\end{array}$ & Same as above \\
\hline \multirow{2}{*}{ 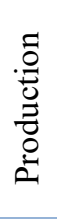 } & $\begin{array}{l}\text { PV } \\
\text { Capacity } \\
\text { Factor }\end{array}$ & $\begin{array}{l}\text { AC capacity factor (including inverter losses) } \\
\text { computed using the System Advisor Model } \\
\text { (Maclaurin et al. 2019) }\end{array}$ & $\begin{array}{l}\text { AC capacity factor increased in daytime hours to } \\
\text { represent the capturing of otherwise-clipped } \\
\text { energy }\end{array}$ \\
\hline & $\begin{array}{l}\text { Storage } \\
\text { Duration }\end{array}$ & $2,4,6,8$, or 10 hours & $\begin{array}{l}\text { One storage duration is assigned to the hybrid } \\
\text { technology for the entire simulation }\end{array}$ \\
\hline \multirow{2}{*}{ 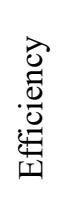 } & $\begin{array}{l}\text { Inverter } \\
\text { efficiency }\end{array}$ & $\begin{array}{l}\text { The inverter is modeled upstream of ReEDS } \\
\text { in SAM }{ }^{11} \text {, and its efficiency }(96 \%) \text { is } \\
\text { included in the PV capacity factors }\end{array}$ & $\begin{array}{l}\text { The inverter is modeled in ReEDS as a limit of the } \\
\text { power produced the hybrid, and its efficiency is } \\
\text { included in the PV capacity factors }\end{array}$ \\
\hline & $\begin{array}{l}\text { Storage } \\
\text { RTE }\end{array}$ & $85 \%$ & $\begin{array}{l}87 \% \text { for PV charging behind the inverter (DiOrio, } \\
\text { Denholm, and Hobbs 2020) }\end{array}$ \\
\hline \multirow{2}{*}{ 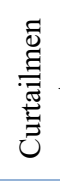 } & Rate (PV) & $\begin{array}{l}\text { Computed endogenously using hourly } \\
\text { profiles }\end{array}$ & $\begin{array}{l}\text { Same as independent, but reduced when the } \\
\text { storage component is charging }\end{array}$ \\
\hline & $\begin{array}{l}\text { Recovery } \\
\text { Rate (Batt) }\end{array}$ & $\begin{array}{l}\text { Computed endogenously based on hourly } \\
\text { dispatch }\end{array}$ & $\begin{array}{l}\text { Computed endogenously based on hourly dispatch, } \\
\text { but limited by local PV generation }{ }^{12}\end{array}$ \\
\hline \multirow{2}{*}{ 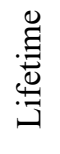 } & PV & 30 years & 30 years, which defines the hybrid plant lifetime \\
\hline & Storage & 15 years & $\begin{array}{l}15 \text { years, such that the battery is refurbished once } \\
\text { during the } 30 \text {-year hybrid plant lifetime. }{ }^{13}\end{array}$ \\
\hline \multirow{2}{*}{ 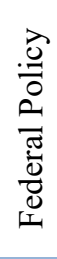 } & PV & $\begin{array}{l}\text { Eligible for the ITC and a } 5 \text {-year Modified } \\
\text { Accelerated Cost Recovery System } \\
\text { (MACRS) }\end{array}$ & Same as independent \\
\hline & Storage & Not eligible for ITC; 7-year MACRS & $\begin{array}{l}\text { ITC and MACRS qualification are applied based } \\
\text { on the amount of battery charging that is assumed } \\
\text { to be derived from the local PV. }\end{array}$ \\
\hline 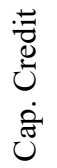 & $\begin{array}{l}\mathrm{PV} \text { and } \\
\text { Storage }\end{array}$ & $\begin{array}{l}\text { Capacity credit is estimated based on } \\
\text { contributions to the top } 10 \text { hours of net load } \\
\text { (in each season) using seven years of hourly } \\
\text { data }\end{array}$ & $\begin{array}{l}\text { Same as independent, but derated to ensure the } \\
\text { total combined capacity credit is less than or equal } \\
\text { to } 1.0 \text {, due to both systems sharing a single inverter }\end{array}$ \\
\hline
\end{tabular}

${ }^{11}$ More information about NREL's System Advisor Model (SAM) is available at https://sam.nrel.gov.

${ }^{12}$ Hybrid resources are represented as storage resources in ReEDS' 8760 dispatch module (Gates et al. under review), and the power capacity is limited to the power capacity of the storage resource. Since dispatch is performed in 24-hour blocks, the total energy input is summed up within each 24-hour period, and the hybrid resource is free to use that energy throughout the day. This simplification is essential for the computational tractability of the algorithm, but imperfectly represents storage operations. For example, the PV+battery hybrid would be able discharge in the morning of a given day, even if it starts out empty and charges in the afternoon to satisfy the daily energy balance.

${ }^{13}$ We represent this refurbishment cost in the objective function for the investment decision and for the operational life of the plant for lifetime-based retirements. At the end of the plant lifetime (i.e., 30 years for a PV plant), ReEDS must choose whether or not to refurbish the entire plant. 


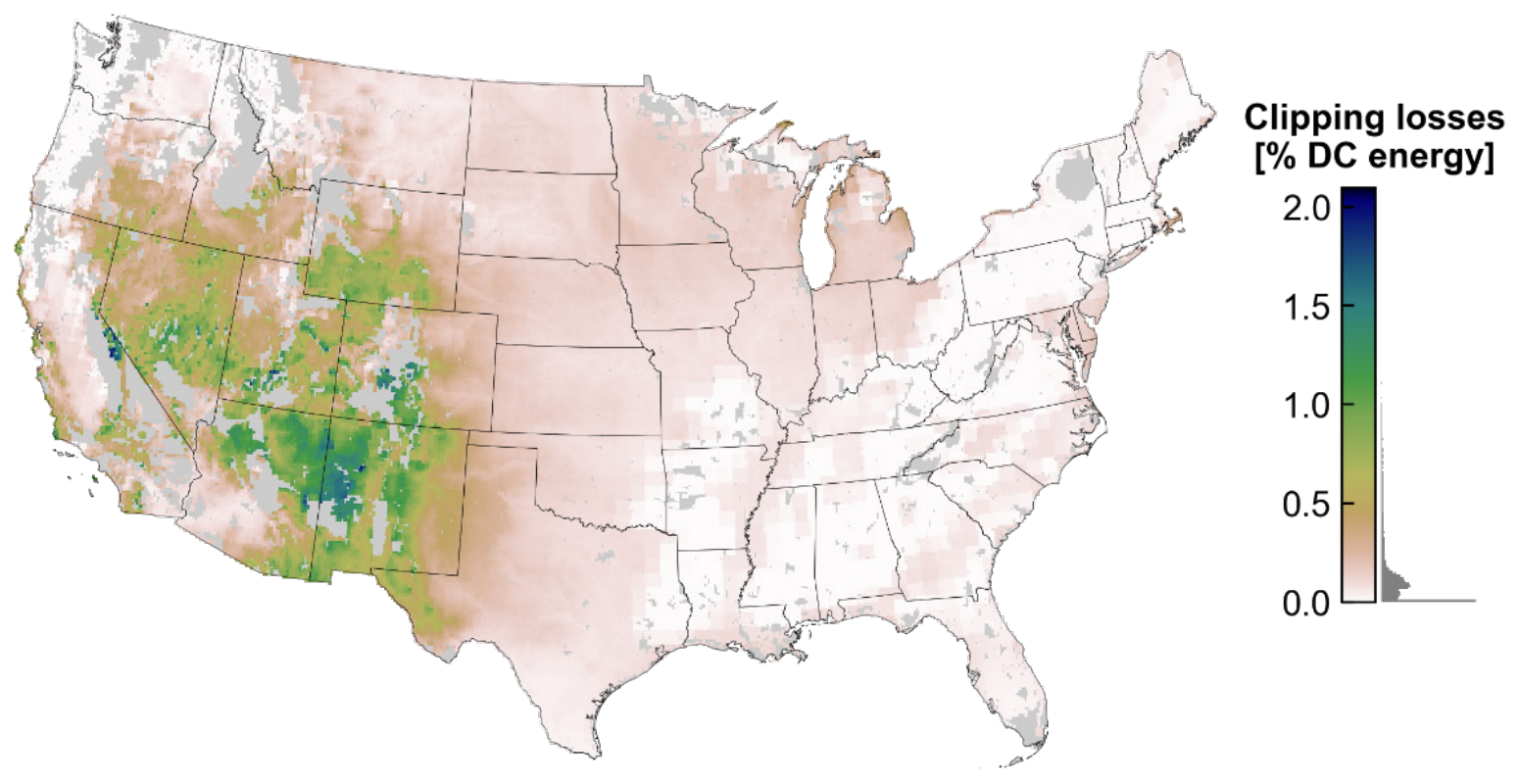

Figure 5. Clipping losses associated with 1.3 ILR systems vary by location but are always less than $3 \%$ of total DC energy produced.

Results shown are simulated using PVWatts Version 7. Values are based on the first year of production.

\subsection{Implementation of PV+Battery in ReEDS}

Figure 6 summarizes the key variables used to represent loosely DC-coupled PV+battery hybrids in ReEDS. In the present study, the entire PV+battery system is defined by the PV array capacity (in $\mathrm{MW}_{\mathrm{DC}}$ terms) and exogenous assumptions about the relative sizing of the inverter and battery component. In other words, for capacity, the ReEDS optimization chooses only the total installed capacity of the PV array, while the battery and inverter specifications are scaled based on the PV capacity selected using pre-defined factors for duration, ILR, and battery-to-inverter ratio (BIR).

For storage charging, we want to know whether the energy storage is being charged from the PV or the grid for several reasons: assigning the appropriate efficiencies for the different charging pathways (related to battery losses), ${ }^{14}$ curtailment recovery potential, and policy qualification. Explicitly tracking the PV versus grid charging sources requires additional variables and constraints (see Appendix A) and thus potentially longer computation times, but it also allows for a more robust representation of hybrid operations.

Ultimately, our new model formulation is defined by the equations that are used to constrain the investment in and operation of PV+battery hybrids. Figure 7 is a representation of how the key operational constraints for $\mathrm{PV}+$ battery hybrids are modeled. A detailed description of incumbent equations for independent $\mathrm{PV}$ and batteries and new equations for interactions of the system components under DC coupling are included in Appendix A.

\footnotetext{
${ }^{14}$ Energy charged directly from the PV does not incur the inverter loss (which is incurred when charging from the grid). Losses between the battery and PV array associated with the DC-to-DC converter are not considered here.
} 


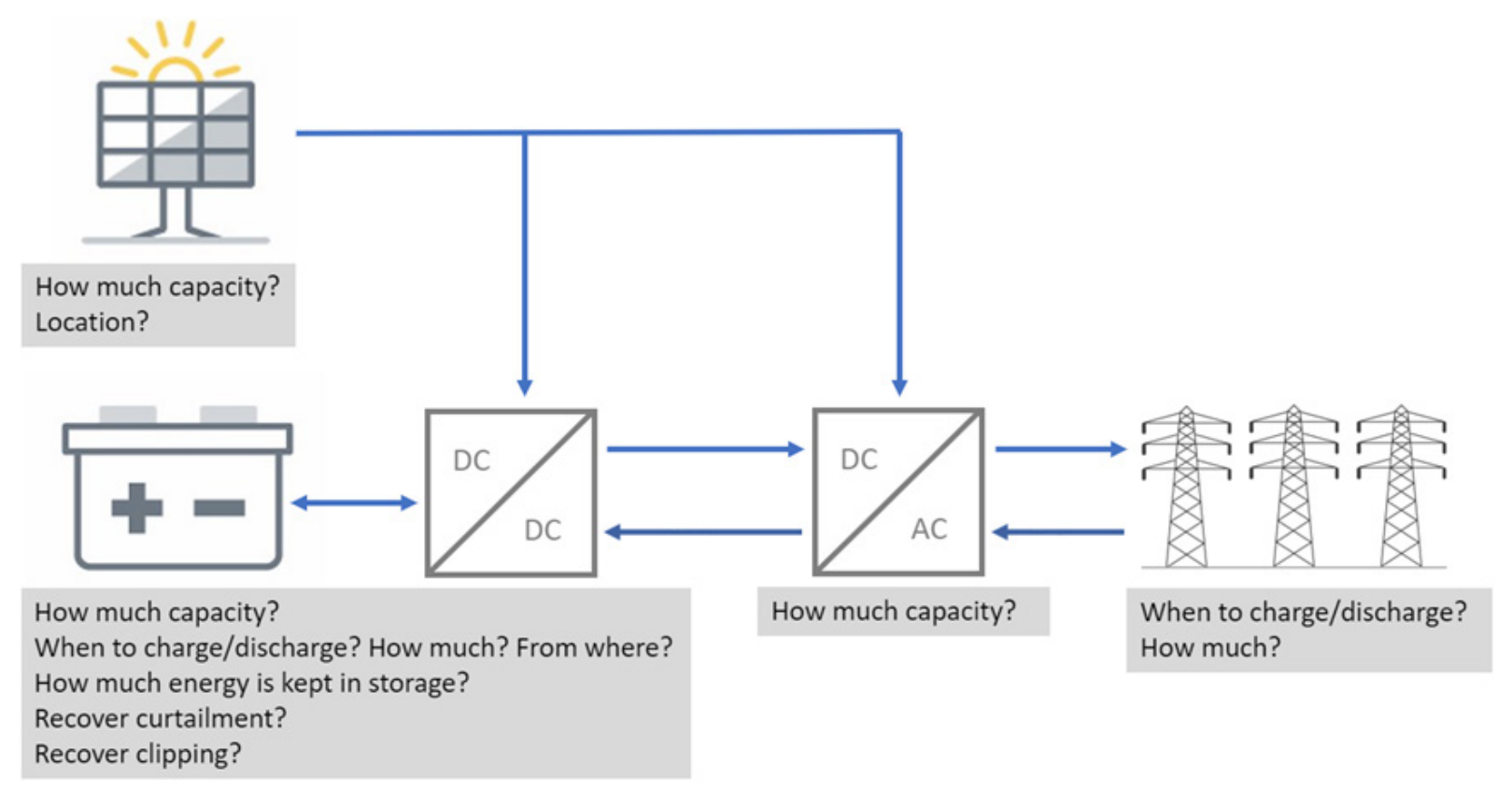

Figure 6. Representation of loosely DC-coupled PV+battery hybrid in ReEDS, including the key investment and operational decision variables.

Energy from the sun ("PV Resource") is converted to DC power at the PV array. Per equation (a) in Figure 7, this energy can be sent straight to the inverter ("PV Gen"), stored in the battery ("Charge[PV]"), or left unused due to curtailment or system losses.

From the perspective of the battery, energy can be stored from the PV or from the grid ("Charge[Grid]"), both of which are subject to storage losses. Energy charged from the grid is further subject to inverter losses, whereas energy charged from PV is not. Energy stored in the battery may be kept in storage, discharged, or used for operating reserves, based on the available battery power capacity (equation $b$ in Figure 7). The amount of energy stored is governed by an inventory balance from adjacent time-slices $(t)$ within the same representative day (equation $\mathrm{c}$ in Figure 7), and it is limited by the storage energy capacity [MWh] (equation d in Figure 7). This formulation allows for tracking of the state (and sources) of charge between adjacent time-slices, and it allows for energy to be shifted across any time-slice within a representative day.

Constraints on the inverter require that the various demands for its utilization ("PV Gen", "Charge[Grid]", "Discharge", and "Reserves") do not exceed the inverter capacity (equation e in Figure 7). The total energy produced by the hybrid is the sum of energy coming directly from the PV array ("PV Gen") and energy discharged from the battery ("Discharge"), as indicated by equation (f) in Figure 7. Only the output that is derived from the local PV will generate new renewable energy certificates (RECs) for state renewable portfolio standards (RPSs), as defined by equation $(\mathrm{g})$ in Figure 7. 


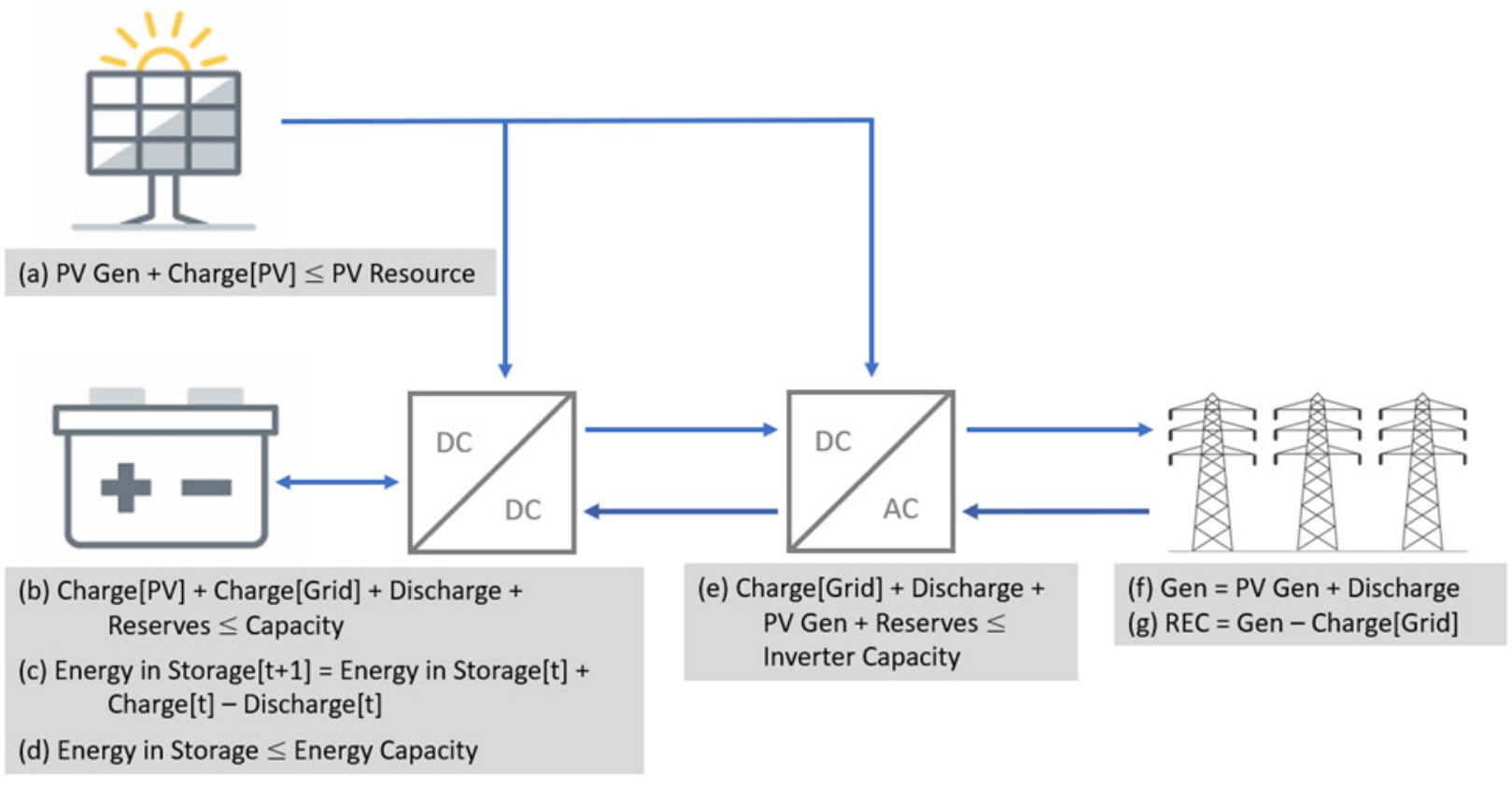

Figure 7. Representation of loosely DC-coupled hybrid PV+battery in ReEDS, including the key operational constraints.

Energy that would have been lost due to clipping occurs on the DC side of the PV system when power available to the inverter exceeds the inverter capacity. In a DC-coupled PV+battery hybrid, otherwise clipped energy can be stored for later use. For an ILR of 1.3, we assume an additional $0.2 \%$ of energy is available during daytime hours - this represents energy that would have been clipped by the inverter in the absence of a DC-coupled battery (Figure 5).

Energy lost due to curtailment occurs on the AC side of the PV system when AC energy downstream of the inverter cannot be used by the grid due to excess electricity supply or transmission congestion. The battery component of the hybrid can be used to store excess supply either from the local PV or from the grid. Outside of the optimization, ReEDS estimates technology curtailment rates specific to each technology, region, and time of day (Gates et al. under review).

In the remainder of this section, we discuss various considerations for representing PV+battery hybrids in ReEDS. The discussion is intended to help other modelers identify approaches that can be most applicable in their own tools regarding the representation of variability and uncertainty (Section 3.4), policy interactions (Section 3.5), different configurations (Section 3.6), and a hybrid comprising technologies with different lifetimes (Section 3.7).

\subsection{Representing Variability and Uncertainty}

Within ReEDS, we treat the variability and uncertainty of VRE resource using three key metrics: capacity credit, curtailment, and induced operating reserve requirements. As discussed in Section 2.1 , the capacity credit of a PV+battery system depends on the configuration and the timing of when firm capacity is needed. Assigning a capacity credit to PV+battery systems can therefore be challenging. 
We implement the capacity credit of PV+battery using the existing ReEDS methods (Frazier et al. 2020; Cole, Greer, et al. 2020). For the battery component of the hybrid, the capacity credit is determined through chronological hourly simulations (between solve years) based on the peaking capacity contribution of all storage resources in the model using seven years of timesynchronous load, wind, and solar data (Frazier et al. 2020). For the PV component of the hybrid, ReEDS uses the same seven years of time-synchronous data to calculate the contribution of PV energy toward the highest 10 net load hours per season. This represents an approximation of the effective load carrying capability of the PV. Finally, these PV and battery capacity credits for PV and battery components of the hybrid are summed and derated such that the capacity credit of the coupled (PV+battery) system does not exceed the shared inverter's rated capacity.

For the curtailment rate, we assume that the PV component of the hybrid has the same curtailment rate as an equivalent independent PV system. The coupled battery can reduce that curtailment by charging during periods when local curtailment is occurring. If the battery is already full or is otherwise energy or capacity limited, then some of the local PV energy will have to be spilled because it cannot be sent to the grid or stored in the battery. Moreover, we are representing a loosely DC-coupled system, so the hybrid's battery component can charge from the grid as well, which might reduce curtailment from other generators, too. ${ }^{15}$

For operating reserves, the addition of PV (or wind) to the system increases the requirement to hold flexibility and regulation reserves (Lew et al. 2013; Cole, Eurek, et al. 2018). We model that interaction by increasing the requirement for operating reserves as PV+battery hybrids are added as well, in the same way that independent PV is treated. However, the storage in that $\mathrm{PV}+$ battery system can fulfill the operating reserve requirement by holding back some of its generation to instead provide operating reserves. Thus, ReEDS can choose whether to meet the extra operating reserve requirement by using the flexibility of the storage that is in the PV+battery system, or by procuring flexibility from some other resource.

\subsection{Policy Interactions}

Under existing statutes, energy storage can be classified as solar energy property and qualify for federal incentives if it is coupled to a PV system that provides at least $75 \%$ of its stored energy (annually) for the first 5 years of operation. If this criterion is met, then the storage technology qualifies for (a) a 5-year Modified Accelerated Cost Recovery System (MACRS), rather than the standard 7-year MACRS and (b) the fraction of the ITC that is equal to the fraction of its annual charging from local PV. ${ }^{16}$ For example, if a battery charges $80 \%$ from the PV to which it is coupled, then the battery would receive $80 \%$ of the ITC's value (based on the ITC schedule).

For loosely DC-coupled systems, accounting can be challenging because the battery can charge from both the local PV and the grid. ${ }^{17}$ In our formulation, we explicitly represent the ITC and MACRS benefits for the loosely DC-coupled PV+battery system by modifying the financing

\footnotetext{
${ }^{15}$ Batteries in tightly DC-coupled systems cannot reduce curtailment from generators other than the PV system to which they are coupled.

16 The depreciable basis is reduced by half when the ITC is applied.

${ }^{17}$ For a tightly DC-coupled system, the accounting is simple because the battery can only charge from the coupled PV; therefore, the battery component would always qualify for both the full ITC value and the 5-year MACRS.
} 
assumptions (to reflect accelerated cost recovery) and reducing battery capital costs (consistent with the ITC schedule). Our formulation allows a user to define the assumed level of ITC qualification, such that scenarios can be designed in which the battery component of PV+battery systems do not, partially, or fully capture the value of the ITC.

Because of the ReEDS model architecture, it is challenging to inform the investment decision based on an assumption that battery operations are restricted for just 5 years out of the total project lifetime (30 years). Our default assumption is that the battery component will not qualify for the ITC, to avoid artificially depressing the cost of systems that are allowed to operate in a way that is inconsistent with the federal incentive. In other words, this assumption is made to ensure consistency with the lack of operational restrictions in our default model formulation (see Appendix C), since we allow the battery component to operate in the way that maximizes its net value (subject to the shared inverter's power rating), without consideration of ITC qualification.

Our approach allows for flexible exploration of the magnitude of influence that different levels of the ITC could have on PV+battery deployment, but it has limitations. First, when the ITC value is applied to the hybrid's battery component, its influence is likely over estimated, since the PV+battery hybrid may not meet the operational requirements for ITC qualification in regions where grid charging is available at relatively low cost. To improve the precision of the ITC modeling, future work could implement the charging requirements associated with ITC qualification during the first five years of PV+battery operations. Second, only one level of ITC qualification can be evaluated within a given scenario, whereas the influence of the ITC on investment decisions will evolve over time. This model representation could be improved by applying an iterative approach where the ITC fraction is determined a priori and adjusted upward or downward based on the modeled operational behavior until convergence; however, convergence could be difficult to achieve on a regional basis.

An additional policy interaction for the PV+battery hybrids arises from state-level renewable portfolio standards or clean energy standards (Barbose 2019). Credits are typically given for each unit of renewable (or clean) energy generation, so the greater the amount of generation from the $\mathrm{PV}+$ battery plant, the more credits the plant can receive. Storage impacts these transactions in two ways: storage can increase effective PV production by capturing otherwise curtailed and otherwise clipped energy (see Section 2.1), but it can also increase losses (if PV energy passes through the storage before being injected into the grid). Therefore, models must be able to capture the value tradeoff between the loss of credits associated with storing the PV energy versus the potentially higher energy revenues from avoided curtailment and clipping and selling the energy at a time that does not coincide with the PV production.

Because of how the portfolio requirements are represented in ReEDS, this tradeoff is captured implicitly within the model. For PV+battery hybrids, we estimate renewable energy certificates (RECs) as the total energy downstream of the inverter minus the energy charged from the grid (equation $g$ in Figure 7), adjusted by the round-trip efficiency. This approach reflects the fact that energy charged from the grid would not be able to qualify for RECs because it would have already received credit for the policy (if applicable) based on the original generation source. 


\subsection{PV+Battery Configurations}

This section discusses system design considerations for the loosely DC-coupled PV+battery systems represented in this report. The ILR and BIR are both design decisions for which the optimal values can vary based on regional resources and grid conditions (Schleifer et al. 2021). In this work, we are representing loosely DC-coupled systems with user-specified ILR and BIR values. As discussed previously, considering additional configurations would require greater complexity, in the form of allowing the model to endogenously choose the ILR and BIR. Our approach can approximate that endogenous choice if the user specifies several ILR and BIR options (e.g., by inputting several discrete configurations within the model and then letting the model choose among those configurations). We used past NREL analyses of PV+battery hybrids (Cowiestoll 2020; Schleifer et al. 2021) to inform the configuration values of the present $\mathrm{PV}+$ battery representation in ReEDS.

Costs are also a function of the design consideration. The potentially nonlinear interactions between costs and system design choices can also impact the model representation. Our discrete choice representation (i.e., pre-determined configurations based on ILR, BIR, and battery duration) allows nonlinear costs to be represented. We represent cost savings as a total cost savings to overnight capital costs and assume that parameters impacting financing costs (e.g., construction time, interest during construction, cost of capital) are the same between hybrid and independent PV and battery systems.

Finally, in the present work, we assume that the land requirement for a hybrid system is the same as for an independent PV system based on separate analysis (Fu, Remo, and Margolis 2018b). Such an assumption is likely appropriate for the full range of possible ILRs for loosely DCcoupled PV+battery hybrids, because our supply curves (and related land-use requirements) are developed based on the $M W_{D C}$ rating. However, any changes to land-use requirements due to the DC-coupled battery are not considered here, as they are not well understood.

\subsection{Tracking Capital Stock with Different Lifetimes}

In ReEDS, the default lifetimes for batteries and PV are 15 years and 30 years, respectively. This difference in lifetimes could be represented as either (a) an automatic refurbishment of the battery after 15 years, to give the system a total lifetime of 30 years, or (b) an endogenous decision in which the model can choose whether to refurbish the battery after its initial 15-year life. In the former approach, the refurbishment cost needs to be seen when the investment decision is made in order to determine the proper trade-off between hybridized and independent $\mathrm{PV}$ and battery systems. If the model foresight is myopic, then including the refurbishment cost up front is important. If the model foresight is perfect, then seeing the refurbishment at 15 years would be preferred. In this work, we assume an automatic refurbishment of the coupled battery technology after 15 years (approach a).

\section{Demonstrating Our PV+Battery Framework}

The primary contribution of this report is the development and documentation of the previously described architecture for evaluating loosely DC-coupled PV+battery hybrids in ReEDS. This architecture can be employed to analyze the future potential for PV+battery systems, but we do not attempt to perform such a detailed analysis here. The outcomes of such an analysis would be 
highly sensitive to assumptions related to the cost and performance of PV+battery hybrids - both now and in the future - which remain highly uncertain. Such exogenous cost assumptions may lead to one technology dominating market share even if the competing investments are almost on par with the dominant investment. Such competition will be especially strong among PV+battery, PV, and battery technologies in ReEDS because we parameterize the former using many of the same cost and performance assumptions as are applied to the latter technologies.

For these reasons, the results presented in this section should not be interpreted as predictions of the future potential for PV+battery systems on the U.S. bulk power system. Rather, they are designed to demonstrate the newly implemented PV+battery capability in ReEDS and explore the relative influence of various cost assumptions.

To benchmark the system changes observed as a result of representing PV+battery hybrids, we include a "No Hybrids" scenario that does not allow PV+battery systems to be built. Relative to this scenario, we explore a range of parametric sensitivities that allow for investments in loosely DC-coupled PV+battery systems with an ILR of 1.3 (based on the PV component only), a BIR of $0.65,{ }^{18}$ and a storage duration of 4 hours (Table 2 ). These values were chosen to be consistent with (a) online and announced PV+battery projects across the conterminous United States (Bolinger, Seel, and Robson 2019; Gorman et al. 2020) and (b) current solar resource inputs for ReEDS. The default cost assumptions for this configuration are derived from the model reported by (Fu, Remo, and Margolis 2018b), which was updated to reflect the specific configuration explored in this report (Table 2).

In Section 4.1, we summarize key trends that arise from our Reference scenario, for which the $\mathrm{PV}+$ battery cost and performance assumptions are defined in the Table 2 . This Reference scenario represents $\mathrm{PV}+$ battery hybrids with only modest changes to the cost and performance parameters associated with the independent technologies, the most impactful of which is a 5\% cost savings associated with DC coupling (relative to the sum of capital costs for comparable independent PV and battery projects).

The Reference scenario serves as a centralized scenario against which to compare results of sensitivities related to assumptions that influence the cost-competitiveness of PV+battery hybrids. In particular, our parametric sensitivity scenarios are defined in the final column of Table 2, and they represent variations related to:

- Assumed cost savings (or increases) associated with DC coupling PV and battery components (compared to independent PV and battery projects; Section 4.2);

- Partial ITC qualification for the battery component (Section 4.3) combined with the range of cost savings (or increases) described in the first bullet; and

- Future cost trajectories for PV and battery technologies (Section 4.4) combined with the range of cost savings (or increases) described in the first bullet.

\footnotetext{
${ }^{18}$ A direct comparison reveals that the battery power capacity (MW) is half that of the PV array (in $\mathrm{MW}_{\mathrm{DC}}$ terms).
} 
Table 2. Key assumptions that define the scenarios and insights in this section.

\begin{tabular}{|c|c|c|}
\hline & Default Assumptions for the Reference Scenario & Sensitivity Ranges Explored \\
\hline \multicolumn{3}{|c|}{ Technical Configuration and Performance Assumptions } \\
\hline ILR (PV only) & 1.3 & $\mathrm{~N} / \mathrm{A}$ \\
\hline $\begin{array}{l}\text { PV Capacity } \\
\text { factor }\end{array}$ & $\begin{array}{l}\text { AC capacity factor adjustment of }+0.2 \% \text {, which } \\
\text { allows energy that would otherwise be clipped to be } \\
\text { represented (accounting for inverter and battery } \\
\text { losses) }\end{array}$ & N/A \\
\hline Battery Size & $\begin{array}{l}\text { Battery-to-inverter ratio }=0.65 \\
\text { Battery duration }=4 \mathrm{hr}\end{array}$ & N/A \\
\hline $\begin{array}{l}\text { Battery Round } \\
\text { Trip Efficiency }\end{array}$ & $\begin{array}{l}85 \% \text { for grid-charging, } 87 \% \text { for PV charging behind } \\
\text { the inverter (DiOrio, Denholm, and Hobbs 2020) }\end{array}$ & N/A \\
\hline $\begin{array}{l}\text { Battery Hourly } \\
\text { Arbitrage Value }\end{array}$ & $\begin{array}{l}\text { The coupled battery receives the same hourly } \\
\text { arbitrage value as a comparable independent battery }\end{array}$ & $\begin{array}{l}\text { The coupled battery's hourly arbitrage } \\
\text { value is decremented by } 10 \% \text { or } 20 \% \\
\text { (Appendix D) }\end{array}$ \\
\hline \multicolumn{3}{|c|}{ Cost Assumptions } \\
\hline $\begin{array}{l}\text { Cost Impacts } \\
\text { Associated with } \\
\text { Hybridization }\end{array}$ & $\begin{array}{l}-5 \% \text { : PV+battery capital costs are reduced by } 5 \% \\
\text { relative to the sum of capital costs for independent } \\
\text { PV and battery systems, based on the } 2020 \text { Annual } \\
\text { Technology Baseline (NREL 2020) }\end{array}$ & $\begin{array}{l}-20 \% \text { and }+10 \% \text { (where negative values } \\
\text { indicate cost savings), providing a } \\
\text { symmetric range around the default } \\
\text { assumption of }-5 \% \text { (Section } 4.2 \text { ) }\end{array}$ \\
\hline $\begin{array}{l}\text { Battery } \\
\text { Qualification } \\
\text { for the } \text { ITC }^{19}\end{array}$ & $\begin{array}{l}\text { The battery component does not qualify for the ITC } \\
\text { and it is free to operate in the way that maximizes } \\
\text { net-value; this default assumption reflects the near- } \\
\text { term stepdown of the ITC value and allows the } \\
\text { battery component to maximize value from energy } \\
\text { arbitrage (based on grid charging) }\end{array}$ & $\begin{array}{l}\text { The battery component qualifies for } \\
\text { 75\% of the ITC value, and: } \\
\text { - No operational constraints are } \\
\text { imposed (Section } 4.3 \text { ); or } \\
\text { - Operational constraints to ensure } \\
\text { ITC qualification (Appendix C). }\end{array}$ \\
\hline $\begin{array}{l}\text { Future PV and } \\
\text { Battery Costs }\end{array}$ & $\begin{array}{l}\text { The Mid Case projection from the } 2020 \text { Annual } \\
\text { Technology Baseline, (ATB Mid) (NREL 2020) }\end{array}$ & $\begin{array}{l}\text { The "Low" Case from the } 2020 \text { ATB } \\
\text { (NREL 2020) (Section 4.4) }\end{array}$ \\
\hline
\end{tabular}

Recall that the default formulation means that sensitivities exploring partial ITC qualification $d o$ not impose a constraint to ensure operations are consistent with policy qualification (see Section 3.5 for discussion). This formulation represents the available option that best represents the potential impact of ITC qualification on PV+battery deployment, due to the short duration of the operational restrictions to ensure ITC qualification (5 years) relative to project lifetime ( 30 years). The impact of this assumption for PV+battery deployment is explored in Appendix C, which presents results based on overly restrictive constraints for battery operations to ensure ITC qualification. Relatedly, the impact of favorable assumptions for the arbitrage value that loosely DC-coupled PV+battery hybrids could capture is explored in Appendix D.

The full range of cost-based sensitivities reflects the significant uncertainty that remains for parameterizing $\mathrm{PV}+$ battery systems, and it is designed to examine tradeoffs between independent and hybrid options. Not all assumptions are meant to be realistic. We explore the relative impacts

${ }^{19}$ The PV component is always fully eligible for the ITC value, consistent with existing policy. 
of these different cost assumptions based on a single key metric, namely the total buildout of PV+battery systems through 2050. Finally, the scenarios presented here all rely on the same model version and input assumptions as used by the Mid-case in the 2020 Standard Scenarios analysis (Cole, Corcoran, et al. 2020) except for the modifications made to represent the hybrid technologies (Section 3). Cost and performance inputs are from the 2020 Annual Technology Baseline (NREL 2020).

\subsection{Reference Scenario Results}

The future deployment of PV+battery hybrids depends on where and what types of grid services are needed, how much of a grid service a resource can provide, and the cost of providing the grid service relative to competing options. Figure 8 shows the evolution of utility-scale PV capacity in hybrid and independent ${ }^{20}$ deployments from 2026 to 2050, under both No Hybrids (left) and Reference (right) assumptions. Under the Reference scenario (which assumes modest cost savings for a loosely DC-coupled system; Table 2), PV+battery deployment begins in the mid2020s (shortly after the technology is first allowed) and grows throughout modeling horizon.

Comparison between the two scenarios reveals similar trends for total utility-scale PV (UPV) capacity over time, which reflects the inherent competition between independent and coupled PV in ReEDS. In other words, the deployment of coupled PV (in the form of PV+battery) largely displaces independent PV, resulting in UPV capacity in 2050 that ranges from $550 \mathrm{GW}_{\mathrm{AC}}$ (No Hybrids) to $580 \mathrm{GW}_{\mathrm{AC}}$ (Reference) in 2050. Under Reference conditions, the share of UPV that is deployed in the hybrid configuration grows over time, ultimately reaching approximately $30 \%$ of total UPV capacity. This magnitude of PV+battery deployment exceeds the $\sim 100 \mathrm{GW}$ that exists in interconnection queues today (Wiser et al. 2020).

Based on our formulation, PV+battery outcompetes its independent counterparts (in some regions and years) for multiple reasons. The 5\% cost savings plays an important role, but it is not the full story. As a test, we ran an additional scenario in which PV+battery costs are equal to the sum of independent PV and battery costs (not shown), which resulted in 90 GW of UPV capacity adopting the hybrid configuration by 2050 . Therefore, in the absence of any cost savings, we find approximately half as much PV+battery deployment by 2050, compared to what is observed for the Reference scenario (Figure 8). This indicates that the hybrid systems' enhanced production (due to the higher PV capacity factor and reduced battery losses compared to independent PV and battery systems) and curtailment recovery are enough to drive deployment in the absence of cost savings associated with DC coupling.

\footnotetext{
${ }^{20}$ For all figures, PV (Independent) represents the sum of the utility-scale PV and distributed utility-scale PV technologies in ReEDS (Brown et al. 2020).
} 


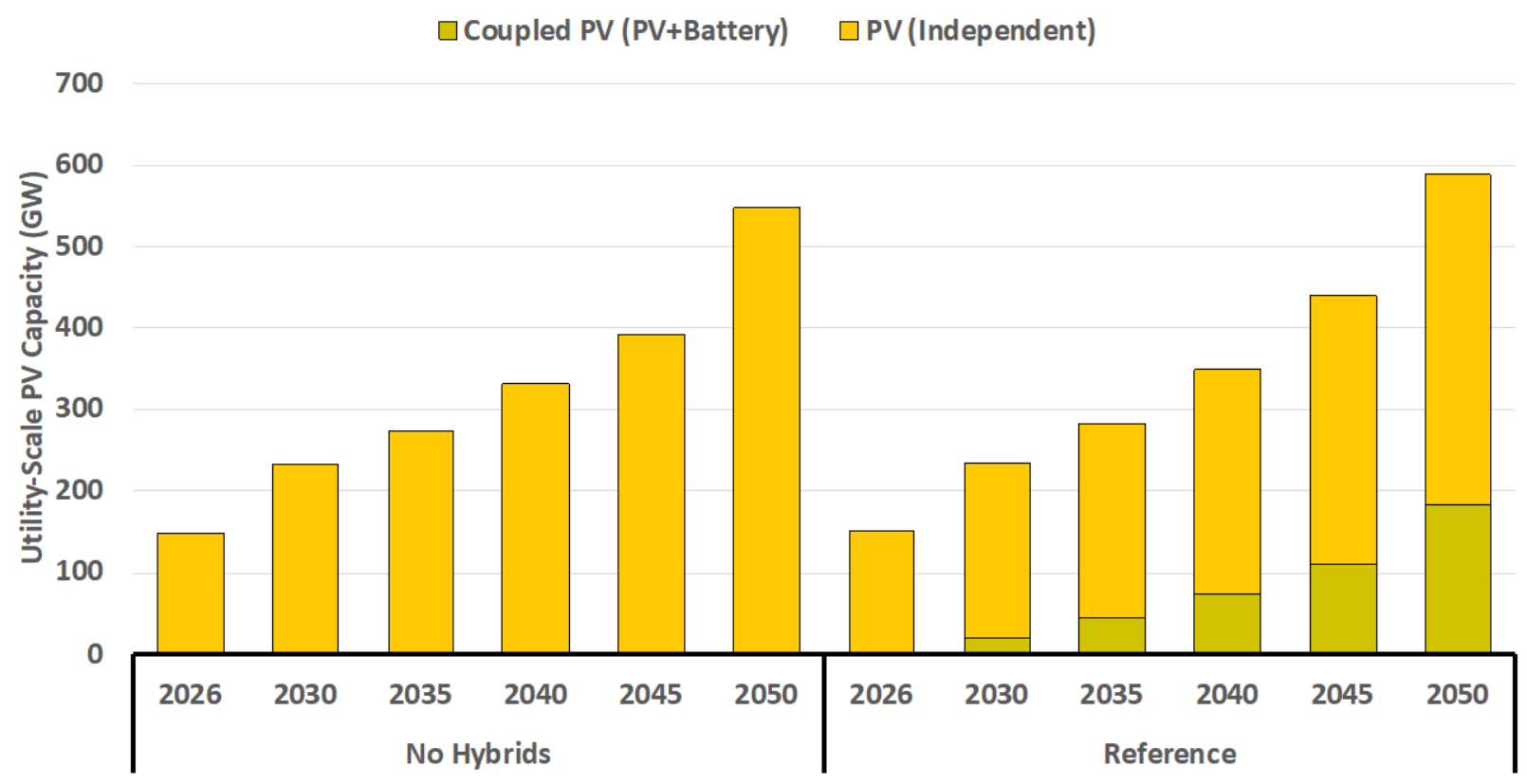

Figure 8. Evolution of utility-scale PV capacity in the "No Hybrids" and Reference scenarios.

Figure 9 shows locations where PV+battery systems are deployed under the Reference scenario assumptions by 2050. Deployment opportunities are not limited to one region, but they are less common in the northernmost states (where solar resource quality is relatively low). The darker shaded regions (indicating areas with greater PV+battery deployment) also correspond to those in which independent PV and/or battery systems are valuable, based on regional diversity in electricity supply (e.g., PV penetration) and demand. Only in select regions (e.g., New York and northeastern Texas) does the ReEDS solution indicate greater competitiveness of independent battery technologies (not shown), which likely reflects the fixed ratio of PV-to-battery capacity in the hybrid configuration.

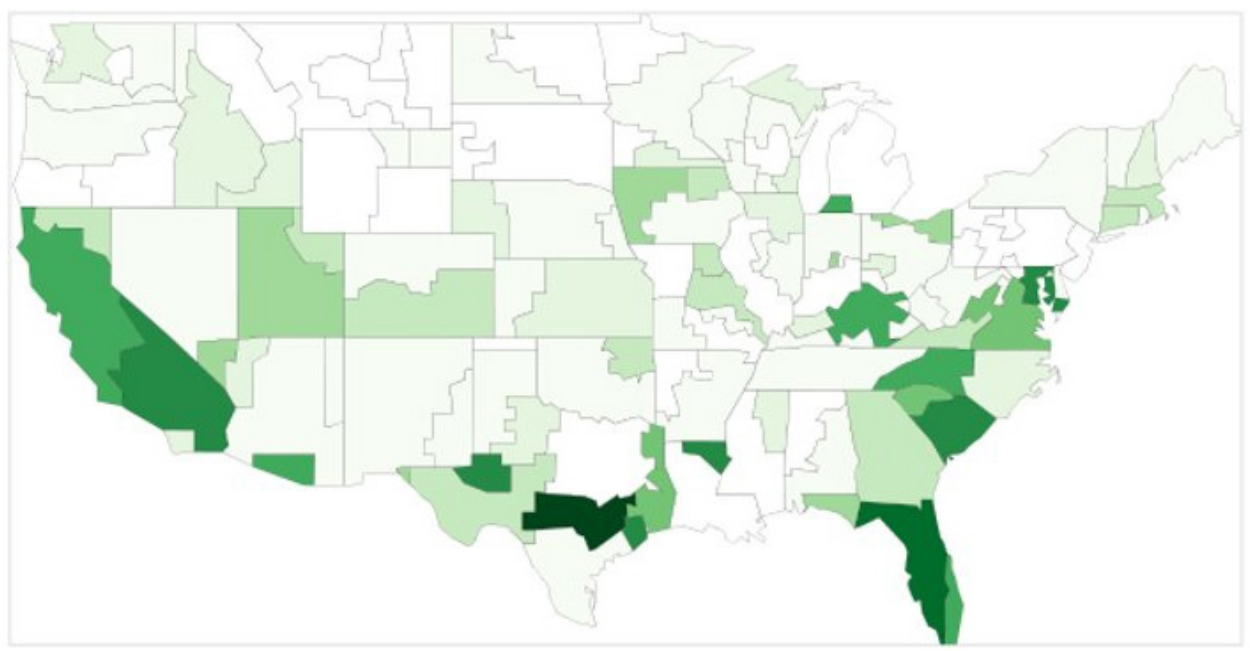

2050 Coupled PV

(PV+Battery)

Capacity $\left(G_{\text {AC }}\right)$

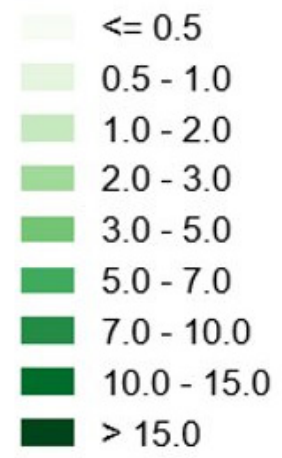

Figure 9. Regional deployment of PV+battery hybrids in the Reference case, where capacity is reported as the PV array capacity in $\mathrm{GW}_{\mathrm{AC}}$. 
The deployment of PV+battery hybrid systems results in the displacement of resources that would have been deployed otherwise, as shown in Figure 10. For all years in which PV+battery systems are deployed, independent PV, 4-hour battery, and 6-hour battery technology deployments are reduced. The competition between PV+battery and independent $P V$ technologies can be thought of as a simple substitution, due to the comparable cost and performance characteristics of the PV components. The competition between PV+battery and independent battery technologies indicates that PV+battery hybrid investments may be driven by the value of peaking resources, and it reflects the fact that the firm capacity contribution of $\mathrm{PV}+$ battery systems is roughly constant in all seasons (because of the battery component).

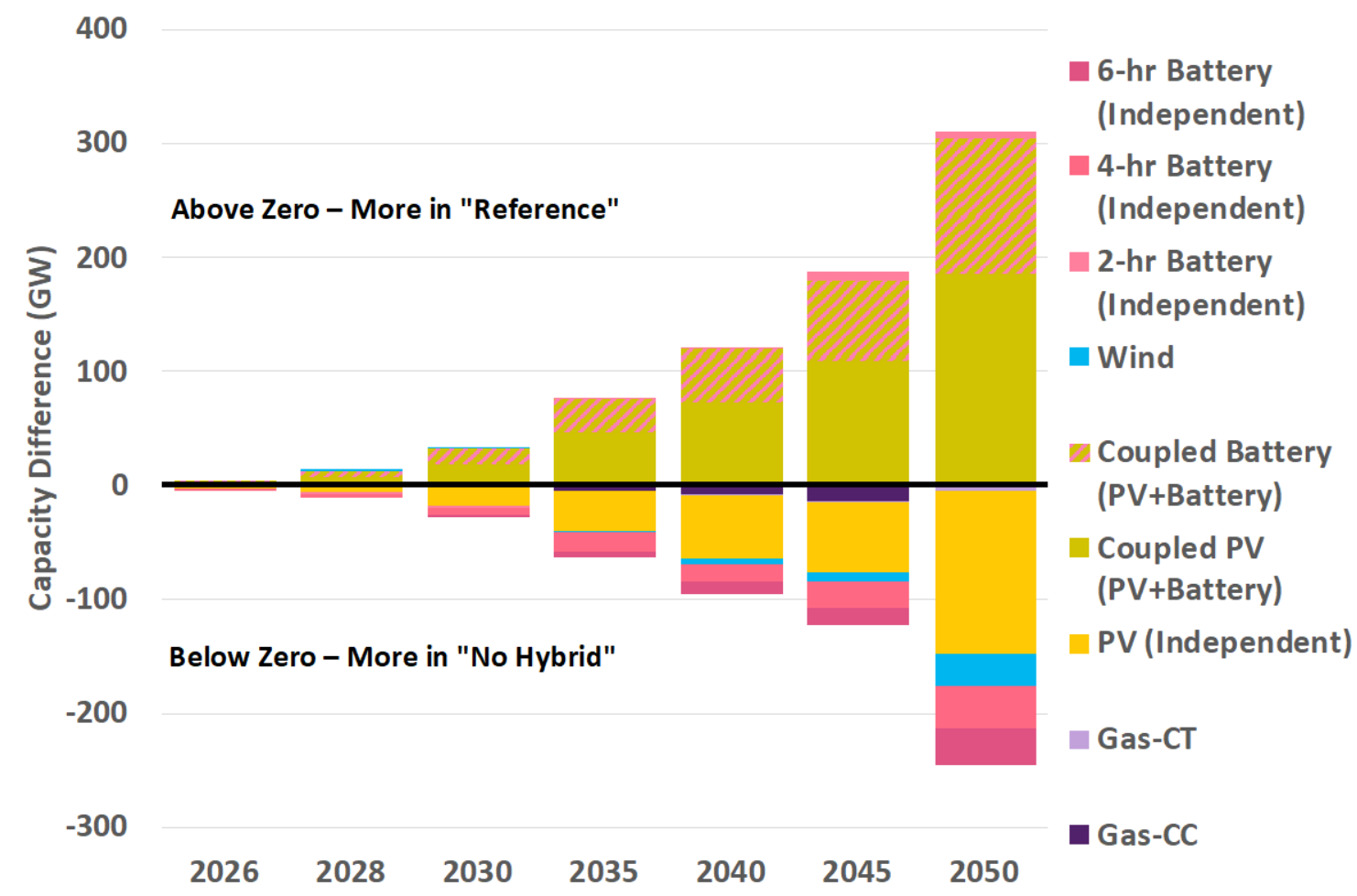

Figure 10. Capacity differences between the Reference and "No Hybrids" scenarios.

Each component of the PV+battery hybrid is reported separately, despite the shared inverter); Gas-CC is natural gas combined cycle; Gas-CT is natural gas combustion turbine.

As PV+battery deployment grows over time, it also leads to more modest displacements of natural gas-fired power plant and wind capacities, along with very modest increases in independent 2-hour battery projects (the top of the stack). The total installed capacity on the bulk power system in these scenarios is on the order of 2,000 GW in 2050, so the capacity displacement observed here is on the order of $12-15 \%$ of total system capacity. ${ }^{21}$ Similar trends are also observed for the annual generation mix (not shown).

\footnotetext{
${ }^{21}$ Note that the appearance of a net increase in total installed capacity is an artifact of our chosen presentation. In Figure 10, PV and battery capacities are reported separately for the hybrid system, despite the fact that they operate behind a shared inverter (meaning that the production from the two components is limited by the inverter). In other words, a PV+battery plant with $130 \mathrm{MW}$ DC PV would be reported as $100 \mathrm{MW}$ of PV (based on the ILR) and $65 \mathrm{MW}$ of battery; however, the total output of the plant would be limited by the $100 \mathrm{MW}$ inverter.
} 
Aggregated operations of all PV+battery hybrids in 2050 are presented in Figure 11 by ReEDS time-slice, including battery charging and discharging. This figure indicates that most battery charging occurs during the morning and afternoon time slices, and it is derived from both the local PV and the grid. The presence of PV-to-battery charging during the daylight hours (grey bars in Figure 11) is primarily driven by the relatively high PV penetration on the grid, which (a) mitigates some of the value associated with sending PV generation directly to the grid and (b) introduces additional value associated with curtailment recovery (from both local and nearby PV plants). ${ }^{22}$ Despite this PV-to-battery charging, some of the local PV resource still goes unused (dark red bars in Figure 11) - particularly in the spring season when demand is relatively lowwhich indicates that a larger battery would be needed to avoid any spilled PV generation.

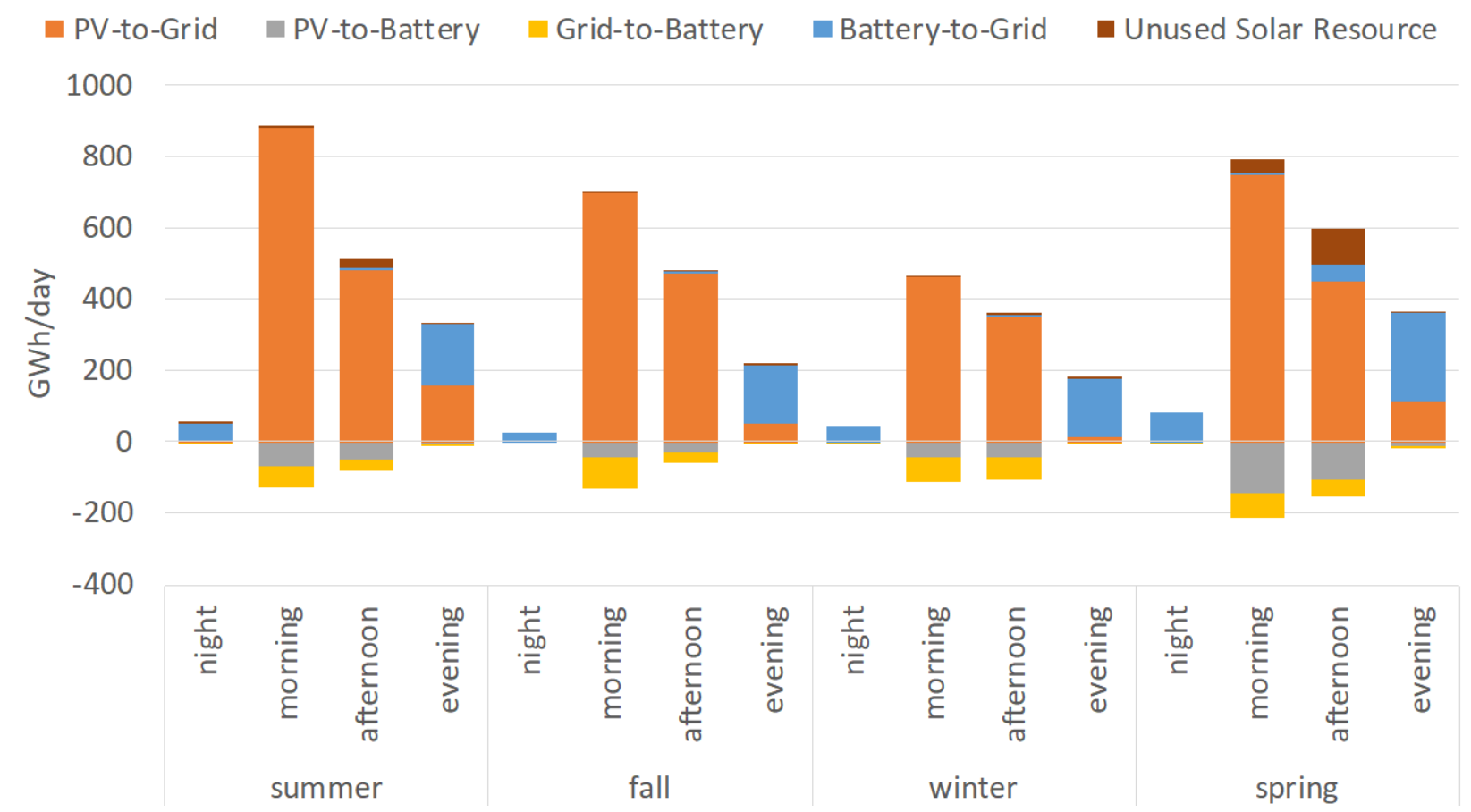

Figure 11. Utilization of the PV+battery hybrid components by ReEDS time-slice for all PV+battery hybrids in 2050 , based on the Reference scenario.

The presence of grid-to-battery charging during daylight hours (yellow bars in Figure 11) indicates that the loosely DC-coupled system's ability to charge from the grid is an important source of flexibility for the assumed PV and battery sizing. In particular, it allows the hybrid's battery component to compete more closely with independent batteries. However, the importance of this flexibility may not extend to PV+battery hybrids with higher ILRs, since such systems would have greater utilization of the inverter capacity and enhanced opportunities to recover clipped energy from the oversized PV arrays.

Finally, it is important to note that while the results presented in Figure 11 are restricted based on the limits of the shared inverter, the arbitrage value of the loosely DC-coupled PV+battery

\footnotetext{
${ }^{22}$ Note that the PV-to-battery charging is influenced more limitedly by the need to recover clipped energy, which is modest throughout most of the conterminous United States with an ILR of 1.3.
} 
system is assumed to be the same as that of independent battery systems. This assumption likely leads to an overestimation of the value that can be realized by loosely DC-coupled PV+battery systems, because it does not account for times when arbitrage value is high but the inverter capacity cannot accommodate available PV generation and arbitrage-related operations. Sensitivities presented in Appendix D show results with incremental derates of the battery component's hourly arbitrage value, which has a noticeable effect on total PV+battery deployment. Better-representing the arbitrage value that can be realized by PV+battery hybrids is a high-priority task for future work in refining this model formulation.

\subsection{The Impact of Cost Savings Associated with Hybridization}

Results from the previous section were based on an assumption that DC coupling PV and battery technologies can reduce capital costs by 5\% (compared to those associated with comparable independent PV and battery projects). In this section, we explore the impacts of different capital cost assumptions for PV+battery systems, including a 20\% decrease and $10 \%$ increase in capital costs (relative to multiple independent systems), which represents a symmetric range around the default assumption of 5\% savings. The range of values explored is meant to provide insights into how sensitive PV+battery deployment is to the effects of hybridization on total plant costs, including whether cost increases could be accommodated based on the potential for increased production (through clipping recovery and higher efficiencies). The significant cost savings explored under the " $-20 \%$ " scenario are meant to incorporate the other potential benefits of hybridization, including those that may not be captured in hybrid system cost estimates from the literature or our model formulation, such as reduced financial risk and increased modularity. ${ }^{23}$

Figure 12 compares installed capacities of PV, battery, and PV+battery technologies in 2050 across our capital cost sensitivity scenarios. Results from the "No Hybrids" and Reference scenarios are identical to those presented in the previous section, and all other scenarios are labeled based on the percentage change in capital cost applied to the sum of independent PV and battery capital costs.

Assuming PV+battery capital costs are $10 \%$ more expensive than the sum of their independent counterparts ("+10\%") results in no hybrid deployment, such that total UPV and independent battery deployment is identical to those in the "No Hybrids" scenario. This indicates that the incremental operational value captured in our representation of loosely DC-coupled PV+battery hybrids does not outweigh a $10 \%$ capital cost increase. However, it is worth noting that this result is specific to our cost and performance assumptions for a single hybrid configuration (for which incremental operational value is expected to be relatively small).

\footnotetext{
${ }^{23}$ ReEDS does not explicitly represent these potential benefits of hybridization, but they can be represented generically as adjustments to the investment cost.
} 

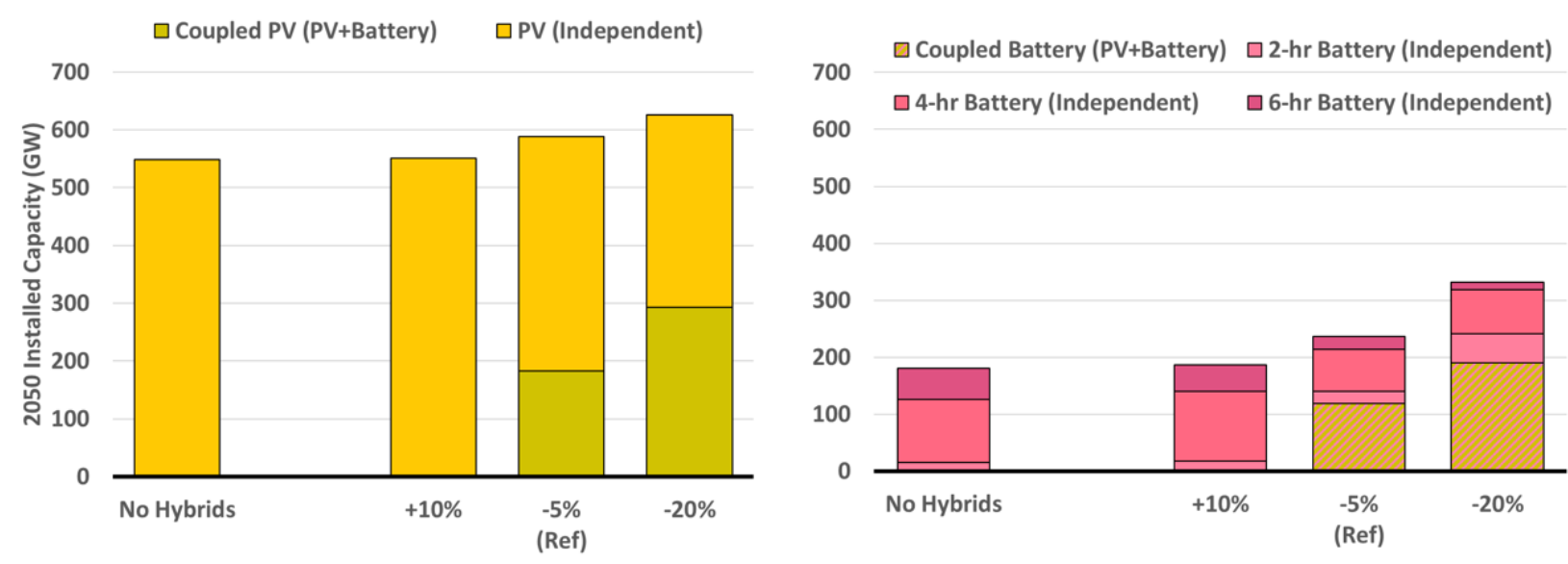

Figure 12. Installed UPV (left) and battery (right) capacity by 2050 for hybrid and independent systems across sensitivities related to the capital cost impacts of hybridization.

Conversely, assuming PV+battery systems' capital costs are significantly less $(-20 \%)$ than the sum of their independent counterparts drives an increase in PV+battery deployment and total utility-scale PV and battery capacity. This growing hybrid deployment displaces a broader mix of generation technologies (including natural gas and wind-based generation), but its dominant effect continues to be displacing independent PV and battery systems. Interestingly, the PV+battery hybrid competes most directly with independent 6-hour batteries, which indicates that coupling with PV may allow a 4-hour battery to compete with its longer-duration counterparts, due to changes in both the capacity credit and the timing and amount of energy produced. Finally, the larger-magnitude cost savings associated with DC coupling in this scenario leads to PV+battery hybrids capturing a growing share of total UPV and battery capacity that is deployed in the hybrid configuration: $30 \%$ of UPV capacity is deployed in the hybrid configuration under the Reference scenario, compared to $\sim 50 \%$ in the " $-20 \%$ " scenario.

Despite the growing deployment of PV+battery hybrids under the " $-20 \%$ " scenario, it is interesting to note that approximately $80 \mathrm{GW}$ of 4-hour battery capacity is deployed in an independent configuration (not coupled to PV). Given the significant cost savings and comparable performance characteristics, the continued deployment of independent 4-hour battery technologies suggests that the shared inverter (which limits the total capacity value and available energy output in a given time-slice) introduces enough of a barrier that an independent battery project is preferred in some regions. Since most of the independent battery technologies are sited in the same regions where PV+battery hybrids are deployed, another potential driver of independent battery deployment is the fixed BIR. In other words, this result indicates that a different BIR (or storage duration) may have been preferred, potentially due to the declining value of the PV+battery hybrid configuration with increasing penetration.

\subsection{The Impact of the ITC}

Literature and industry discussions indicate that the ITC is a prominent driver of interest in PV+battery hybrids in the near term (Hledik et al. 2019; Gramlich, Goggin, and Burwen 2019; Gorman et al. 2020). Based on the December 2020 legislative updates, the policy schedule dictates that the ITC value steps down from the current $26 \%$ level to a $22 \%$ level (for projects 
commencing construction in 2023), and any project coming online after 2025 can only receive the $10 \%$ ITC level (DOE 2020).

The previously presented results have not applied the ITC value to the battery component, in order to avoid a potential inconsistency between the investment decision and (unrestricted) operational characteristics for the PV+battery technology in ReEDS. The sensitivities presented in this section are designed to explore how impactful this assumption is, considering only changes to the battery component's partial (75\%) ITC qualification on PV+battery costs (in the absence of an operational constraint). As before, this ITC modification is combined with all capital cost assumptions in Table $2(-20 \%,-5 \%,+10 \%)$. Additional sensitivities presented in Appendix $\mathrm{C}$ explore the effects of combining overly restrictive operational constraints with partial ITC qualification for the battery component.

For a given level of assumed capital cost savings associated with DC coupling, we find that the dominant effect of allowing the battery component to partially qualify for the ITC is a modest acceleration in PV+battery deployment. This means that we continue to see no deployment when assuming DC coupling results in a 10\% increase in capital costs, even if the battery component's capital costs are reduced based on partial ITC qualification. On the other hand, when combined with the $-5 \%$ and $-20 \%$ capital cost assumptions, the battery component qualifying for the ITC drives a modest acceleration in PV+battery deployment, which is increased by 2-3 GW in 2026 under the $75 \%$ ITC scenarios (compared to the corresponding scenarios in which the battery component does not receive the ITC). This accelerated deployment is consistent with the higher value of the ITC incentive for projects coming online prior to 2026.

Despite this near-term acceleration in PV+battery deployment, total installed capacities in 2050 under the scenarios in which the battery component partially qualifies for the ITC are comparable to those presented in Figure 12 (above). This result may reflect the fact that for the vast majority (2026-2050) of our thirty-year simulation period, allowing the battery component to partially qualify for the ITC only lowers the battery component's financing costs by about $5.7 \%$ according to the financing methodologies applied in ReEDS (Brown et al. 2020). Alternatively, it could indicate that future cost declines for the PV and battery components outweigh the near-term impact of the ITC, so future deployment overshadows near-term ITCinduced deployment. In either case, the effects of the ITC may be more apparent in prescribed builds, based on current interconnection queue and planned project data; this would allow for $\mathrm{PV}+$ battery deployment based on projects that are already under construction (prior to when we have defined the technology as being available in ReEDS), which can capture the highest ITC levels. It is also important to note that the results presented here would likely not hold in an ITC extension scenario, i.e., if one were to assume that the ITC policy's schedule were extended by a decade or more (Cole, Frazier, et al. 2018).

Recall that the scenarios in this section do not include an operational constraint to require that battery operations be consistent with ITC qualification (i.e., at least $75 \%$ of the energy used to charge the coupled battery is sourced from the local PV for the first five years of operation). To assess the appropriateness of this aspect of our model formulation, we explore the extent to which the value-maximizing operations of the battery are inherently consistent with ITC qualification through post-processing. In particular, we quantify the share of battery charging that is derived from local PV under the Reference scenario, in which the battery is allowed to 
operate in whatever way produces the greatest value. This calculation is performed for all new $\mathrm{PV}+$ battery hybrids in all years, so the following results reflect an evolving range of grid mixes (and PV penetrations). Based on the first year of operation for new PV+battery systems over the 2020-2050 modeling horizon, we find that:

- $29 \%$ of PV+battery hybrids qualify for a partial $(27 \%)$ or full (2\%) ITC, since the battery component receives at least $75 \%$ of its energy from the local PV (on an annual basis).

- $71 \%$ of PV+battery hybrids do not qualify for the ITC, since the battery component receives less than $75 \%$ of its energy from the local PV (Figure 13).

This result indicates that in the absence of an operational constraint, most PV+battery plants throughout the country operate in a way that is inconsistent with ITC qualification (Figure 13). In other words, if a PV+battery plant has the ability to charge from the grid, then it can achieve the greatest value by utilizing that capability for energy arbitrage (based on grid charging) and recovering curtailment from non-local PV. This result supports (and informed) our default assumption that the battery component does not qualify for the ITC. However, it does not reflect a cost-benefit assessment of the reduced value in the first 5 years of operations (cost) against the immediate ITC benefit (value); therefore, this post-processing result likely underestimates the influence of the ITC, particularly for planned near-term PV+battery projects. Finally, sensitivity results presented in Appendix $\mathrm{C}$ point to a similar conclusion, that PV+battery hybrids in ReEDS do not operate in a way that is consistent with the battery component's partial ITC qualification unless required to do so.

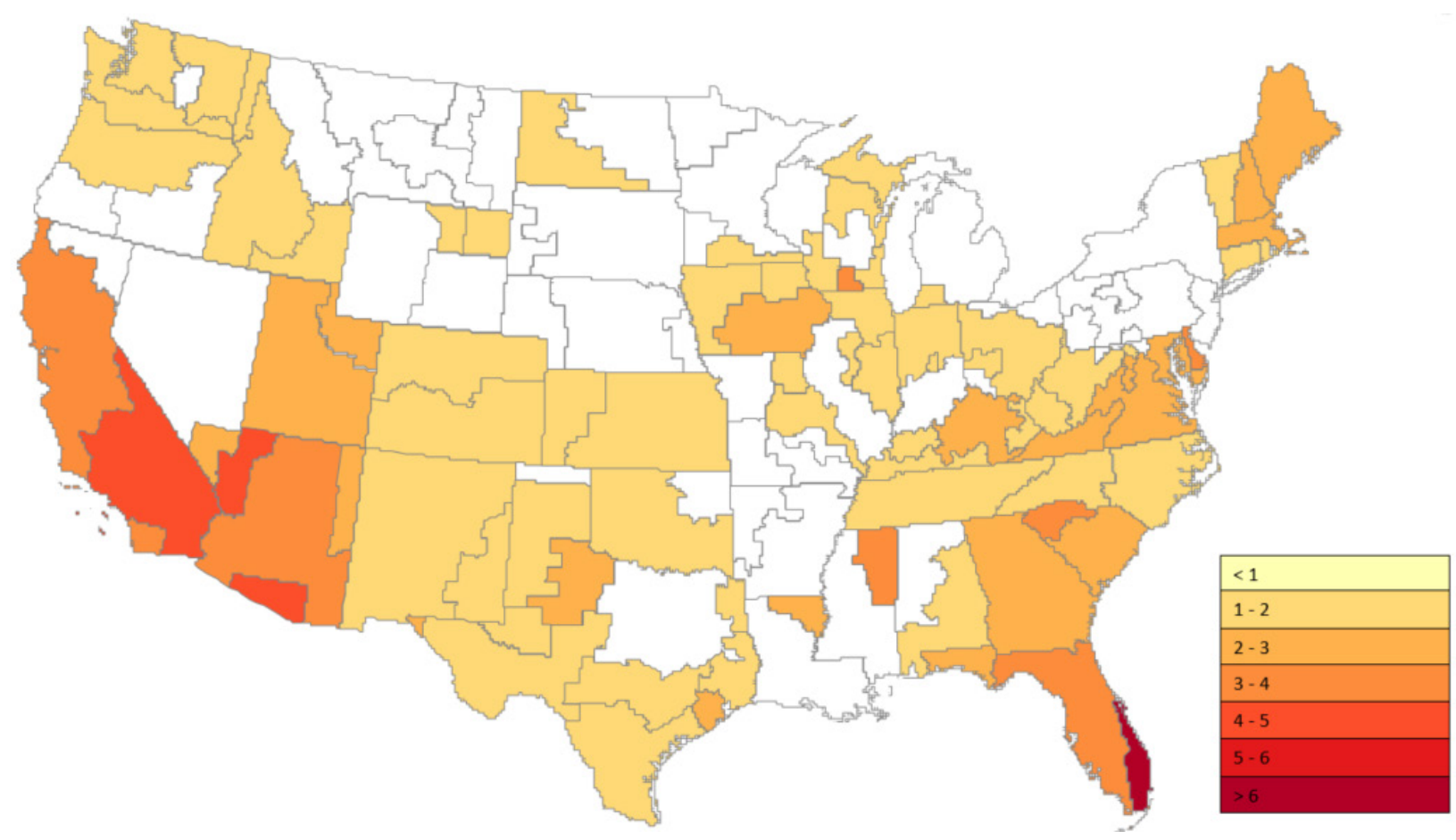

Figure 13. Number of PV+battery systems whose dispatch characteristics do not meet the ITC requirement in the first year of operation (2020-2050) under the Reference Scenario. 


\subsection{The Impact of Cost Trajectories for PV and Battery Technologies}

The economic case for $\mathrm{PV}+$ battery hybrids is rooted in instances (locations) where having the qualities of both technologies is beneficial. This depends not only on the benefits of hybridization, but also the relative costs and values of the independent technologies. This section explores how sensitive the future potential of PV+battery hybrids is to cost and performance improvements for the independent technologies over time. In particular, we modify our capital cost (and performance) trajectories for UPV and battery technologies to follow the ATB Low scenario (NREL 2020). This modification is further combined with the full range of hybridization-related cost assumptions presented in Section $4.2(-20 \%,-5 \%$, and $+10 \%)$.

As before, no PV+battery deployment is observed under the $+10 \%$ capital cost assumptions, even when they are combined with the ATB Low trajectories. Therefore, the remainder of this section will present and describe results for combining hybrid cost savings with varying cost and performance trajectories for UPV and battery technologies.

Comparing the ATB Mid and ATB Low versions for any capital cost assumption reveals that improved cost and performance trajectories for UPV and battery technologies drive a pronounced increase in their total installed capacities (i.e., the height of the stacked bars). For each capital cost assumption presented in Figure 14, total installed UPV capacity in 2050 is $60 \%$ greater under the ATB Low cost and performance trajectories (compared to the corresponding ATB Mid results). Similar trends are observed for battery technologies, although the comparison is more nuanced due to the different storage durations available.

Another noticeable trend in Figure 14 is that the ATB Low scenario drives loosely DC-coupled $\mathrm{PV}+$ battery hybrids to capture a larger share of total utility-scale PV and battery deployments. In particular, one-half and two-thirds of total UPV capacity is deployed in the hybrid configuration under the $-5 \%$ (Reference) and $-20 \%$ cost assumptions (respectively); in both cases, this represents a 15-percentage point increase compared to the corresponding scenarios with ATB Mid assumptions. Therefore, more rapid cost and performance improvements for PV and battery technologies tend to tip the scales in favor of hybrid deployments under our representation of the loosely DC-coupled PV+battery system. 
$\square$ Coupled PV (PV+Battery) $\quad \square$ PV (Independent)

1,200

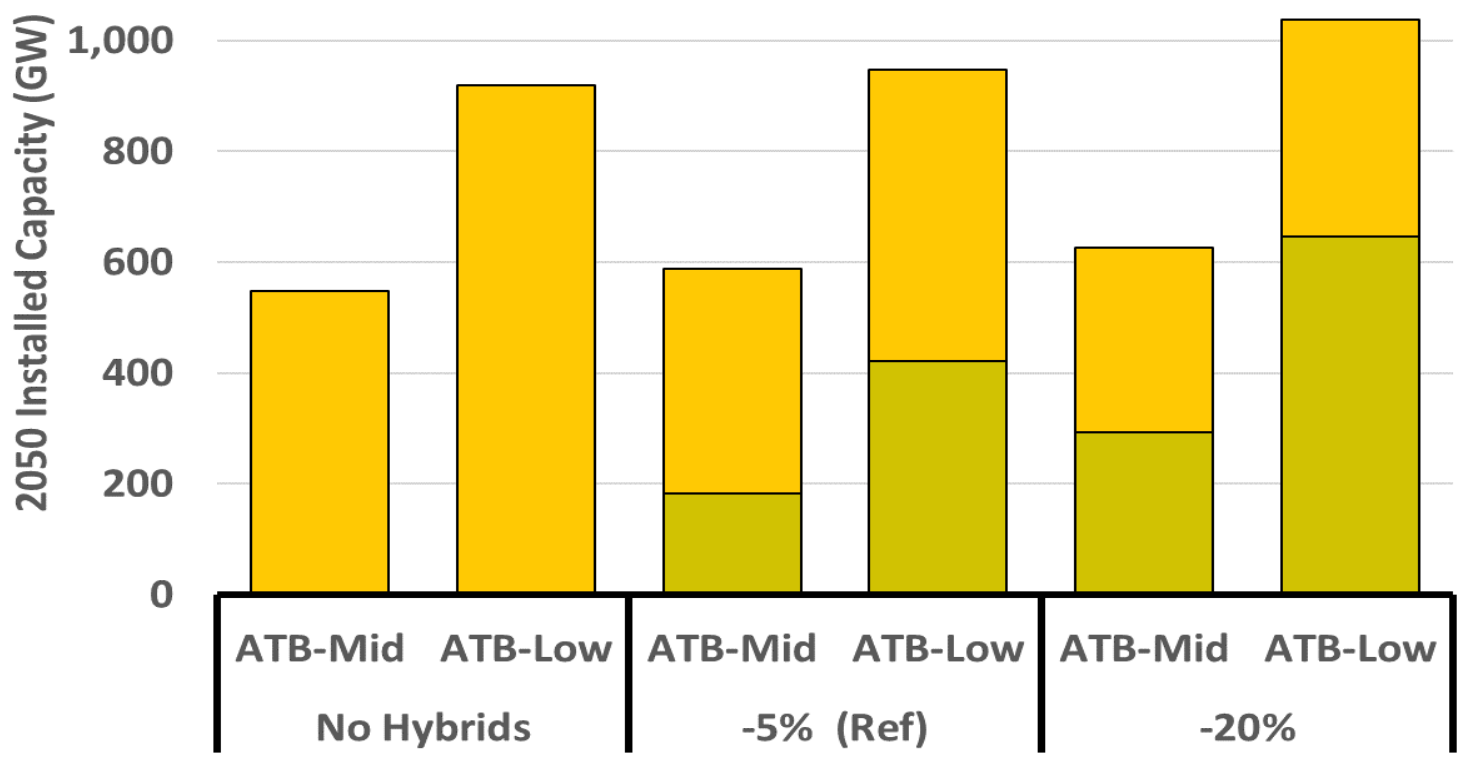

1,200

Coupled Battery (PV+Battery) $\square$ 2-hr Battery (Independent)

$\square$ 4-hr Battery (Independent) $\quad \square$ 6-hr Battery (Independent)

(1)

1,000

800

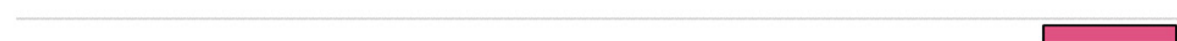

0

\begin{tabular}{|c|c|c|}
\hline ATB-Mid ATB-Low & ATB-Mid & ATB-Low \\
No Hybrids & $-5 \%$ (Ref) & $-20 \%$
\end{tabular}

Figure 14. Installed UPV (top) and battery (bottom) capacities in 2050 for hybrid and independent systems across different levels of cost savings combined with varying assumptions for future cost and performance of PV and battery technologies. 


\section{Conclusions and Future Work}

In this work, we respond to the growing industry interest in PV+battery hybrids by incorporating these systems into a capacity expansion model. In particular, we describe and demonstrate our newly-employed methods for representing a loosely DC-coupled PV+battery technology in the ReEDS capacity expansion model. Significant uncertainties about the cost and operations of $\mathrm{PV}+$ battery systems inhibit our ability to perform a comprehensive analysis of their deployment potential, but we explore a suite of parametric sensitivity scenarios that inform which input assumptions have the greatest influence on deployment of our selected PV+battery configuration.

From the full suite of scenarios, we find that PV+battery deployment could occur throughout the conterminous United States if there are cost savings associated with DC coupling PV and battery technologies (sharing a single bi-directional inverter). Total PV+battery capacity in 2050 is highly sensitive to the level of cost savings that can be achieved through DC coupling and future cost and performance trajectories for PV and battery technologies. If greater cost savings can be achieved through DC coupling (e.g., due to a growing amount of shared balance-of-system costs, reduced financial risk, or modularity) or more rapid cost and performance improvements are realized for PV and battery technologies, then total PV+battery deployment and its share of total utility-scale PV and battery capacity grows (e.g., to more than 50\% of total UPV capacity).

In all cases, growing PV+battery deployment primarily displaces independent PV and battery technologies, indicating the strong competition between the hybrid and independent configurations with similar performance characteristics. Finally, we find that applying the ITC to the battery component could accelerate near-term deployment of PV+battery hybrids, based on the legislative updates in December 2020.

While the modeling representation of PV+battery hybrids and demonstration scenarios in this report are valuable contributions to the ReEDS modeling suite and capacity expansion modeling community, there are several ways in which the modeling may be improved. Although the specifics here focus on how the representation can be improved in ReEDS, many of the improvements discussed apply to capacity expansion models more generally.

\subsection{Additional sensitivities}

This report presents an initial set of sensitivity scenarios related to the current and future costs associated with a single PV+battery configuration (with an ILR of 1.3, BIR of 0.65 , battery duration of 4 hours, and loose DC coupling). Another important dimension for sensitivity analysis lies in the configuration itself, including the BIR, storage duration, and ILR.

First, shorter or longer storage durations and larger or smaller battery-to-inverter ratios could offer greater net benefits in different regions, based on the tradeoff between investment costs and operational value (e.g., capacity credit and the magnitude and timing of energy production). The current formulation can support sensitivities related to storage duration and battery-to-inverter ratios, but only one option can currently be explored in a given scenario.

Second, PV+battery hybrids may involve significantly larger ILRs in the future, in order to enhance the ability to recover otherwise-clipped energy. However, the current PV capacity factors in ReEDS represent AC energy downstream of the inverter, so clipping losses are 
inherently embedded in these capacity factors. By converting the ReEDS model to use hourly DC production from the PV array as the model input (rather than hourly capacity factors), we would achieve more flexibility in representing any configuration and improve the ability to represent clipping recovery. Such development would further enable scenario analysis related to the economic performance of DC-coupled PV+battery hybrids as a function of ILR.

In addition, the dominant type of coupling between PV and battery technologies remains unknown. Compared to the loosely DC-coupled configuration explored here, AC-coupled systems (which utilize separate inverters for each component) are (a) less complex to deploy and enable greater capacity value (due to the use of separate inverters), but (b) lack the ability to recover otherwise-clipped energy. AC-coupled PV+battery systems could be explored in ReEDS by linking the native PV and battery technologies without any modifications to their performance characteristics, which would reveal the regions where co-deployment of PV and battery technologies is valuable (and could potentially be achieved at a lower system cost).

Tightly DC-coupled systems may have lower costs than their loosely coupled counterparts (because of the use of a shared $P V$ inverter), but they also likely have lower operational value (because the coupled battery must charge from the local PV, thus removing the potential for hourly arbitrage of grid energy and reducing the capacity credit). The capacity credit and curtailment calculations developed for this work can be modified for a tightly DC-coupled PV+battery technology in ReEDS by estimating the battery component's peaking capacity potential based on available energy (using the appropriate PV resource profile to charge the hybrid's battery component). Then, the maximum depth of discharge can be used to determine the duration that a hybrid resource would need to receive full capacity credit; if this is longer than four hours, then the capacity credit of the hybrid resource would need to be derated accordingly. ${ }^{24}$ Finally, the charging and discharging constraints would need to be revisited to disallow grid charging, and cost assumptions would need to reflect the use of a PV inverter.

\subsection{Improve the representation of the hybrid system's battery component}

There are limitations of our current representation of the hybrid system's battery component: (a) we allow it to realize the same hourly arbitrage value as an independent battery, and (b) we do not constrain it to charge in a way that is consistent with ITC qualification. To the former point, a top priority for improving our representation of loosely DC-coupled PV+battery hybrids is to explore methods for calculating a more accurate hourly arbitrage value. Given the relatively high value of arbitrage, the hourly calculation between solve steps can be modified to derate the hourly arbitrage value for the coupled battery technologies by removing the hours during which the inverter capacity is saturated by the PV (i.e., hourly arbitrage would violate the shared inverter constraints).

Representing the battery component's qualification for the ITC could be incrementally improved by enforcing operational requirements consistent with ITC qualification (i.e., requiring at least

\footnotetext{
${ }^{24}$ For example, if it is determined that a PV+battery hybrid resource would need 5 hours of duration to receive a full capacity credit (due to insufficient solar resource), the hybrid would only receive a capacity credit of $80 \%$ applied to the 4-hour portion of peak demand.
} 
$75 \%$ of the stored energy to be derived from the coupled PV for the first 5 years of the $\mathrm{PV}+$ battery lifetime). The representation could further be improved by modifying the capacity credit, curtailment, and hourly arbitrage value calculations to consider the ITC requirement. In particular, the model could weigh the incremental value of avoided curtailment against the potential for lost value if it leads to less than $75 \%$ of the stored energy originating from the coupled PV during the first five years.

Beyond these incremental improvements, the ITC framework for PV+battery systems in ReEDS can be improved to make operational decisions related to ITC qualification endogenous. However, this would be complicated by the 5-year requirement for charging from the local PV, the exact means of accounting used to prove that proper charging has taken place, and the risk tolerance of the operator coupled with the minimum charging requirement of $75 \%$. The traditional structure of making the ITC a nonlinear function of the amount charged from qualifying resources is inherently incompatible with the linear programming structure of ReEDS.

Finally, storage degradation is currently handled in ReEDS via higher fixed O\&M costs (Cole and Frazier 2020). However, degradation is a function of battery utilization, so making that relationship endogenous within the model would improve the representation of battery storage technologies in general. For the hybrid system in particular, it would allow PV+battery systems to choose between curtailing energy and putting energy into storage.

\subsection{Incorporate prescribed PV+battery capacity and near-term future builds}

The ReEDS model represents any plants that are currently under construction as prescribed builds. PV and battery systems are treated separately in that process, meaning that a hybrid plant would appear in ReEDS as independent PV and battery plants (in the current structure). Given the continually improving data on hybrid plants in interconnection queues, the prescribed builds in ReEDS can be updated to include prescribed PV+battery plants.

\subsection{Model the retrofitting of existing PV sites with the addition of a battery}

We do not currently model retrofits of independent PV or independent battery systems to form PV+battery hybrids, but the model has the architecture to do so. Retrofits may benefit from an accelerated interconnection process - particularly for tightly DC-coupled systems, which only entail an increase in energy output and not a change in demand (from grid-charging of storage) or peak output. Aside from the ITC qualification, the most challenging aspect of modeling retrofits is properly accounting for plant age, such that the model does not retrofit a plant that is at the end of its lifetime. Moreover, in practice, retrofitting an existing plant may be more likely to take the form of an AC-coupled system, ${ }^{25}$ which is distinct from the loosely DC-coupled system presented in this report.

\footnotetext{
${ }^{25}$ There are multiple reasons for this, including that (a) one inverter will already be in place (which negates the potential for cost-savings associated with a shared inverter) and (b) DC-coupled PV+battery systems require the
} 
Relatedly, because the battery component lifetime (15 years) is half that of the PV component (30 years), it might be optimal for the battery retrofit that occurs at 15 years to happen at a different size. For example, if a system originally had a BIR of 0.65 , perhaps at the 15 -year retrofit it would be optimal to retrofit with a BIR of 1.0. Such an upgrade is not possible with the current representation, but it could be added in the future.

Additionally, as PV plants retire, they can be refurbished without paying the spur line transmission cost because the spur line already exists from the previous plant. Future work could allow PV+battery systems to be rebuilt on the sites of prior builds and, therefore, not have to reincur the spur line cost.

\subsection{Incorporate region-specific PV+battery configurations}

The current ReEDS representation includes one hybrid configuration with an ILR of 1.3 and a BIR of 0.65 . Alternative configurations may provide greater system benefits, relative to both competing technologies and the incumbent hybrid configuration. All candidate configurations could be prescreened in a price-taker model to determine a subset of configurations that may offer the greatest system benefits for a particular region under existing and future grid mixes.

\subsection{Size all system components endogenously}

Currently, ReEDS sizes the inverter and storage relative to the size of the PV array (using the ILR and BIR). By restructuring the formulation, some or all of these components (PV, inverter, and storage) could be turned into separate decision variables. Linearizing the choice of BIR would allow the optimization to explore how the ideal battery size evolves over time for a given ILR. Determining the optimal ILR endogenously would create a more complex formulation, but it would let the model consider the full range of configurations and, in turn, reveal whether different configurations are chosen under different future conditions. Whether this additional complexity is justified is unclear, since the same type of configuration may be chosen in most or all scenarios, such that a more limited set of configurations would have been sufficient.

\subsection{Evaluate the role of PV+battery in $100 \%$ renewable energy grids}

Recent studies indicate that while substantial levels of renewable energy penetration are feasible, both real and modeling challenges occur when approaching 100\% renewable energy generation (Hand et al. 2012; Kroposki et al. 2017; Cole and Frazier 2018; B. Frew et al. 2019). For example, the capacity credit of diurnal energy storage falls to zero or near-zero at very high penetrations of storage, when net load is flat for multiple days (Denholm et al. 2020; Frazier et al. 2020). Future work could explore the role of hybrids in these transformational scenarios, especially in terms of accelerating the deployment of PV and battery technologies and lowering system costs.

battery component to be located next to the PV arrays, whereas an AC-coupled system can involve positioning the battery component on the outskirts of the solar field. 


\section{References}

Ahlstrom, Mark, Andrew Gelston, Jeffrey Plew, and Lorenzo Kristov. 2019. "Hybrid Power Plants - Flexible Resources to Simplify Markets and Support Grid Operations." https://www.esig.energy/wp-content/uploads/2019/10/Hybrid-Power-Plants.pdf.

Barbose, Galen. 2019. "U.S. Renewables Portfolio Standards: 2019 Annual Status Update." Lawrence Berkeley National Laboratory. https:/emp.lbl.gov/sites/default/files/2019annual-rps-summary-report.pdf.

Bistline, John, and David Young. "Economic drivers of wind and solar penetration in the US." Environmental Research Letters 14, no. 12 (2019): 124001.

Bolinger, Mark, Joachim Seel, and Dana Robson. 2019. "Utility-Scale Solar: Empirical Trends in Project Technology, Cost, Performance, and PPA Pricing in the United States (2019 Edition)." https://emp.lbl.gov/sites/default/files/lbnl_utility_scale_solar_2019_edition_final.pdf.

Brown, Maxwell, Wesley Cole, Kelly Eurek, Jon Becker, Dave Bielen, Ilya Chernyakhovskiy, Stuart Cohen, et al. 2020. "Regional Energy Deployment System (ReEDS) Model Documentation: Version 2019.” NREL/TP-6A20-74111. Golden, CO: National Renewable Energy Laboratory. https://doi.org/10.2172/1505935.

California ISO. 2019. "Hybrid Resources Issue Paper." http://www.caiso.com/Documents/IssuePaper-HybridResources.pdf.

Cole, Wesley, Sean Corcoran, Nathaniel Gates, Daniel Mai, Trieu, and Paritosh Das. 2020. "2020 Standard Scenarios Report: A U.S. Electricity Sector Outlook." NREL/TP-6A2077442. Golden, CO: National Renewable Energy Laboratory. https://www.nrel.gov/docs/fy21osti/77442.pdf.

Cole, Wesley, Kelly P. Eurek, Nina M. Vincent, Trieu T. Mai, Gregory L. Brinkman, and Matthew Mowers. 2018. "Operating Reserves in Long-Term Planning Models." NREL/PR-6A20-71148. Golden, CO: National Renewable Energy Laboratory. https://doi.org/10.2172/1455165.

Cole, Wesley, and A. Will Frazier. 2018. "Impacts of Increasing Penetration of Renewable Energy on the Operation of the Power Sector." The Electricity Journal, Special Issue: Energy Policy Institute's Eighth Annual Energy Policy Research Conference, 31 (10): 24-31. https://doi.org/10.1016/j.tej.2018.11.009.

Cole, Wesley, A. Will Frazier, Paritosh Das, Trieu Mai, and Paul Donohoo-Vallett. 2018. "2018 Standard Scenarios Report: A U.S. Electricity Sector Outlook.” NREL/TP-6A20-71913. Golden, CO: National Renewable Energy Laboratory. https://doi.org/10.2172/1481848.

Cole, Wesley, and Will A. Frazier. 2020. "Cost Projections for Utility-Scale Battery Storage: 2020 Update.” Technical Report NREL/TP-6A20-75385. Golden, CO: National Renewable Energy Laboratory. https://www.nrel.gov/docs/fy20osti/75385.pdf.

Cole, Wesley, Bethany Frew, Pieter Gagnon, Andrew Reimers, Jarett Zuboy, and Robert Margolis. 2018. "Envisioning a Low-Cost Solar Future: Exploring the Potential Impact of Achieving the SunShot 2030 Targets for Photovoltaics." Energy 155 (July): 690-704. https://doi.org/10.1016/j.energy.2018.04.166.

Cole, Wesley, Daniel Greer, Jonathan Ho, and Robert Margolis. 2020. "Considerations for Maintaining Resource Adequacy of Electricity Systems with High Penetrations of PV and Storage." Applied Energy 279 (December): 115795. https://doi.org/10.1016/j.apenergy.2020.115795. 
Cowiestoll, Brady L. 2020. "Contributions of Solar + Storage to Future Power Needs." NREL/PR-6A20-74962. National Renewable Energy Lab. (NREL), Golden, CO (United States). https://www.osti.gov/biblio/1605091.

Denholm, Paul, and Trieu Mai. 2019. "Timescales of Energy Storage Needed for Reducing Renewable Energy Curtailment.” Renewable Energy 130 (C). https://doi.org/10.1016/j.renene.2018.06.079.

Denholm, Paul, Robert Margolis, and Joshua Eichman. 2017. "Evaluating the Technical and Economic Performance of PV Plus Storage Power Plants.” Renewable Energy, 36.

Denholm, Paul, Joshua Novacheck, Jennie Jorgenson, and Matthew O'Connell. 2016. "Impact of Flexibility Options on Grid Economic Carrying Capacity of Solar and Wind: Three Case Studies.” NREL/TP-6A20-66854. National Renewable Energy Lab. (NREL), Golden, CO (United States). https://www.nrel.gov/docs/fy17osti/66854.pdf.

Denholm, Paul, Jacob Nunemaker, Pieter Gagnon, and Wesley Cole. 2020. "The Potential for Battery Energy Storage to Provide Peaking Capacity in the United States." Renewable Energy 151 (May): 1269-77. https://doi.org/10.1016/j.renene.2019.11.117.

DiOrio, Nicholas, Paul Denholm, and William B. Hobbs. 2020. "A Model for Evaluating the Configuration and Dispatch of PV plus Battery Power Plants." Applied Energy 262 (March): 114465. https://doi.org/10.1016/j.apenergy.2019.114465.

DOE. 2020. "Guide to the Federal Investment Tax Credit for Commercial Solar Photovoltaics." DOE/EE-2006. U.S. Department of Energy Energy Efficiency and Renewable Energy. https://www.energy.gov/sites/prod/files/2020/01/f70/Guide\%20to\%20the $\% 20$ Federal $\% 2$ 0Investment\%20Tax\%20Credit\%20for\%20Commercial\%20Solar\%20PV.pdf.

Eberle, Annika, Owen Roberts, Alicia Key, Parangat Bhaskar, and Katherine Dykes. 2019. "NREL's Balance-of-System Cost Model for Land-Based Wind." NREL/TP-6A2072201. National Renewable Energy Lab. (NREL), Golden, CO (United States). https://www.nrel.gov/docs/fy19osti/72201.pdf.

Elgqvist, Emma, Kate Anderson, and Edward Settle. 2018. "Federal Tax Incentives for Energy Storage Systems." National Renewable Energy Laboratory. https://www.nrel.gov/docs/fy18osti/70384.pdf.

English, Jeffrey, Taco Niet, Benjamin Lyseng, Victor Keller, Kevin Palmer-Wilson, Bryson Robertson, Peter Wild, and Andrew Rowe. 2020. "Flexibility Requirements and Electricity System Planning: Assessing Inter-Regional Coordination with Large Penetrations of Variable Renewable Supplies." Renewable Energy 145 (January): 2770 82. https://doi.org/10.1016/j.renene.2019.07.097.

Ericson, Sean, Eric Rose, Harshit Jayaswal, Wesley Cole, Jill Engel-Cox, Jeffrey Logan, Joyce McLaren, et al. 2017. "Hybrid Storage Market Assessment." NREL/MP-6A50-70237. Joint Institute for Strategic Energy Analysis. https://www.nrel.gov/docs/fy18osti/70237.pdf.

Fälth, Hanna Ek, Dan Atsmon, Lina Reichenberg, and Villhelm Verendel. 2020. "MENA Compared to Europe: The Influence of Land Use, Nuclear Power, and Transmission Expansion on Renewable Electricity System Costs," March. https://arxiv.org/abs/2003.08882v1.

Feldman, David, and Robert Margolis. 2020. "Q1/Q2 2020 Solar Industry Update.” https://www.nrel.gov/docs/fy20osti/77772.pdf.

Feldman, David, Matthew Zwerling, and Robert Margolis. 2019. "Q2/Q3 2019 Solar Industry Update.” NREL/PR-6A20-75484. https://www.nrel.gov/docs/fy20osti/75484.pdf. 
FERC. 2020. "Technical Conference Regarding Hybrid Resources." Docket No. AD20-9-000, Washington, D.C., July 23. https://www.ferc.gov/news-events/events/technicalconference-regarding-hybrid-resources-docket-no-ad20-9-000-07232020.

Frazier, A. Will, Wesley Cole, Paul Denholm, Daniel Greer, and Pieter Gagnon. 2020.

"Assessing the Potential of Battery Storage as a Peaking Capacity Resource in the United States." Applied Energy 275 (October): 115385. https://doi.org/10.1016/j.apenergy.2020.115385.

Frew, Bethany A., Wesley J. Cole, Yinong Sun, Trieu Mai, and James Richards. 2017. "8760Based Method for Representing Variable Generation Capacity Value in Capacity Expansion Models.” NREL/CP-6A20-68869. National Renewable Energy Lab. (NREL), Golden, CO (United States). https://www.nrel.gov/docs/fy17osti/68869.pdf.

Frew, Bethany, Wesley Cole, Paul Denholm, A. Will Frazier, Nina Vincent, and Robert Margolis. 2019. "Sunny with a Chance of Curtailment: Operating the US Grid with Very High Levels of Solar Photovoltaics." IScience 21 (November): 436-47. https://doi.org/10.1016/j.isci.2019.10.017.

Fu, Ran, Ted L James, Donald Chung, Douglas Gagne, Anthony Lopez, and Aron Dobos. 2015. "Economic Competitiveness of U.S. Utility-Scale Photovoltaics Systems in 2015: Regional Cost Modeling of Installed Cost $(\$ / \mathrm{W})$ and LCOE (\$/KWh).” In 2015 IEEE 42nd Photovoltaic Specialist Conference (PVSC), 1-11. https://doi.org/10.1109/PVSC.2015.7356261.

$\mathrm{Fu}$, Ran, Timothy Remo, and Robert Margolis. 2018a. "Evaluating the Cost Benefits of U.S. Utility-Scale Photovoltaics Plus Energy Storage Systems." In 2018 IEEE 7th World Conference on Photovoltaic Energy Conversion (WCPEC) (A Joint Conference of 45th IEEE PVSC, 28th PVSEC 34th EU PVSEC), 1-4. https://doi.org/10.1109/PVSC.2018.8547852.

$\mathrm{Fu}$, Ran, Timothy W. Remo, and Robert M. Margolis. 2018b. "2018 U.S. Utility-Scale Photovoltaics-Plus-Energy Storage System Costs Benchmark.” NREL/TP-6A20-71714. National Renewable Energy Lab. (NREL), Golden, CO (United States). https://doi.org/10.2172/1483474.

Gates, Nathaniel, Wesley Cole, A. Will Frazier, and Pieter Gagnon. under review. "Evaluating the Interactions Between Variable Renewable Energy and Diurnal Storage." Applied Energy.

Gorman, Will, Andrew Mills, Mark Bolinger, Ryan Wiser, Nikita G. Singhal, Erik Ela, and Eric O'Shaughnessy. 2020. "Motivations and Options for Deploying Hybrid Generator-plusBattery Projects within the Bulk Power System." The Electricity Journal 33 (5): 106739. https://doi.org/10.1016/j.tej.2020.106739.

Gramlich, Rob, Michael Goggin, and Jason Burwen. 2019. "Enabling Versatility: Allowing Hybrid Resources to Deliver Their Full Value to Customers." Energy Storage Association. https://energystorage.org/wp/wp-content/uploads/2019/09/2019.9.16GridStrategies-ESA-White-Paper-on-Hybrid-Resources.pdf.

Hand, M. M., S. Baldwin, E. DeMeo, J. M. Reilly, T. Mai, D. Arent, G. Porro, M. Meshek, and D. Sandor. 2012. "Renewable Electricity Futures Study. Volume 1. Exploration of HighPenetration Renewable Electricity Futures." NREL/TP-6A20-52409-1. National Renewable Energy Lab. (NREL), Golden, CO (United States). https://doi.org/10.2172/1219711. 
Hirth, Lion. 2013. "The Market Value of Variable Renewables." Energy Economics 38: 218-36. http://dx.doi.org/10.1016/j.eneco.2013.02.004.

. 2015. "The Optimal Share of Variable Renewables:How the Variability of Wind and Solar Power Affects TheirWelfare-Optimal Deployment." The Energy Journal 36 (1): 127-62. http://dx.doi.org/10.5547/01956574.36.1.5.

Hledik, Ryan, Roger Leuken, Judy Chang, Hannes Pfeifenberger, Jesse Cohen, and John Imon Pedtke. 2019. "Solar-Plus-Storage: The Future Market for Hybrid Resource." December. https://brattlefiles.blob.core.windows.net/files/17741_solar_plus_storage_economics_final.pdf.

Ho, Jonathan L., Wesley J. Cole, and Evangelia Spyrou. 2017. "ReEDS-Mexico: A Capacity Expansion Model of the Mexican Power System.” NREL/TP-6A20-70076. Golden, CO: National Renewable Energy Laboratory. https://doi.org/10.2172/1398375.

Jean, Joel, Michael Woodhouse, and Vladimir Bulović. 2019. "Accelerating Photovoltaic Market Entry with Module Replacement.” Joule 3 (11): 2824-41. https://doi.org/10.1016/j.joule.2019.08.012.

Jones-Albertus, Rebecca, Wesley Cole, Paul Denholm, David Feldman, Michael Woodhouse, and Robert Margolis. 2018. "Solar on the Rise: How Cost Declines and Grid Integration Shape Solar's Growth Potential in the United States." MRS Energy \& Sustainability 5. https://doi.org/10.1557/mre.2018.4.

Kroposki, B., B. Johnson, Y. Zhang, V. Gevorgian, P. Denholm, B. M. Hodge, and B. Hannegan. 2017. "Achieving a 100\% Renewable Grid: Operating Electric Power Systems with Extremely High Levels of Variable Renewable Energy." IEEE Power and Energy Magazine 15 (2): 61-73. https://doi.org/10.1109/MPE.2016.2637122.

Lew, D., G. Brinkman, E. Ibanez, B. M. Hodge, M. Hummon, A. Florita, and M. Heaney. 2013. "The Western Wind and Solar Integration Study Phase 2." NREL/TP-5500-55588. National Renewable Energy Lab. (NREL), Golden, CO (United States). https://doi.org/10.2172/1095399.

Maclaurin, Galen, Nick Grue, Anthony Lopez, and Dona Heimiller. 2019. "The Renewable Energy Potential (ReV) Model: A Geospatial Platform for Technical Potential and Supply Curve Modeling." NREL/TP-6A20-73067. Golden, CO: National Renewable Energy Laboratory. https://www.nrel.gov/docs/fy19osti/73067.pdf.

Mai, Trieu, Wesley Cole, Nathaniel Gates, and Daniel Greer. 2021. "The Prospective Impacts of 2019 State Energy Policies on the U.S. Electricity System." Energy Policy 149 (February): 112013. https://doi.org/10.1016/j.enpol.2020.112013.

Martinez, Andrew, Kelly Eurek, Trieu Mai, and Andrew Perry. 2013. "Integrated Canada-US Power Sector Modeling with the Regional Energy Deployment System (ReEDS)." Technical Report NREL/TP-6A20-56724. Golden, CO: National Renewable Energy Laboratory. http://www.nrel.gov/docs/fy13osti/56724.pdf.

Mills, Andrew, and Pia Rodriguez. 2019. "Drivers of the Resource Adequacy Contribution of Solar and Storage for Florida Municipal Utilities." Lawrence Berkeley National Laboratory. https://emp.lbl.gov/publications/drivers-resource-adequacy.

Mills, Andrew, and Ryan Wiser. 2012. "Changes in the Economic Value of Variable Generation at High Penetration Levels: A Pilot Case Study of California." LBNL-5445E. Ernest Orlando Lawrence Berkeley National Laboratory. https://emp.lbl.gov/sites/all/files/lbnl5445e.pdf. 
MISO Energy Storage Task Force. 2019. "Market Participation Model for a Generating Facility with Multiple Fuel Sources (Hybrid Resources)."

https://cdn.misoenergy.org/20190523\%20ESTF\%20Hybrid\%20Storage\%20Issue\%20List \%20-\%20Submission\%20Form341397.pdf.

Murphy, C. A., A. Schleifer, and K. Eurek. 2021. "A Taxonomy of Systems That Combine Utility-Scale Renewable Energy and Energy Storage Technologies." Renewable and Sustainable Energy Reviews 139 (April): 110711. https://doi.org/10.1016/j.rser.2021.110711.

Murphy, Caitlin, Yinong Sun, Wesley J. Cole, Galen J. Maclaurin, Craig S. Turchi, and Mark S. Mehos. 2019. "The Potential Role of Concentrating Solar Power within the Context of DOE's 2030 Solar Cost Targets.” NREL/PR-6A20-72717. National Renewable Energy Lab. (NREL), Golden, CO (United States). https://www.osti.gov/biblio/1506623potential-role-concentrating-solar-power-within-context-doe-solar-cost-targets.

NREL. 2020. “2020 Annual Technology Baseline.” Golden, CO: National Renewable Energy Laboratory. https://atb.nrel.gov/.

NREL, Sandia National Laboratory, SunSpec Alliance, and SuNLaMP PV O\&M Best Practices Working Group. 2018. "Best Practices for Operation and Maintenance of Photovoltaic and Energy Storage Systems; 3rd Edition.” NREL/TP-7A40-73822. https://www.nrel.gov/docs/fy19osti/73822.pdf.

Rose, Amy, Ilya Chernyakhovskiy, Joseph Palchak, Samuel Koebrich, and Mohit Joshi. LeastCost Pathways for India's Electric Power Sector. NREL/TP-6A20-76153. National Renewable Energy Lab (NREL), Golden, CO (United States), 2020.

Schleifer, Anna H., Caitlin A. Murphy, Wesley J. Cole, and Paul L. Denholm. 2021. "The Evolving Energy and Capacity Values of Utilierty-Scale PV-plus-Battery Hybrid System Architectures." Advances in Applied Energy, March, 100015. https://doi.org/10.1016/j.adapen.2021.100015.

Sepulveda, Nestor A., Jesse D. Jenkins, Fernando J. de Sisternes, and Richard K. Lester. "The role of firm low-carbon electricity resources in deep decarbonization of power generation." Joule 2, no. 11 (2018): 2403-2420.

Serdio Fernández, Francisco, Miguel Angel Muñoz-García, and Susanne Saminger-Platz. 2016. "Detecting Clipping in Photovoltaic Solar Plants Using Fuzzy Systems on the Feature Space." Solar Energy 132 (July): 345-56. https://doi.org/10.1016/j.solener.2016.03.013.

US EIA, DOE. 2021. “Assumptions to the Annual Energy Outlook 2021: Renewable Fuels Module." EIA.

Wiser, Ryan, Mark Bolinger, Will Gorman, Joe Rand, Seongeun Jeong, Joachim Seel, Cody Warner, and Ben Paulos. 2020. "Hybrid Power Plants: Status of Installed and Proposed Projects.” 34197. Lawrence Berkeley National Lab. (LBNL), Berkeley, CA (United States). https://emp.lbl.gov/publications/hybrid-power-plants-status-installed. 


\section{Appendix A. Formulation}

Table 3 summarizes the key variables used to represent loosely DC-coupled PV+battery systems in ReEDS. In the present study, the entire PV+battery system is defined by the PV array capacity (in $\mathrm{MW}_{\mathrm{DC}}$ terms) and exogenous assumptions about the relative sizing of the inverter and battery component. To implement this approach, the ReEDS capacity variable "CAP" refers to only the DC rating of the PV array. ${ }^{26}$

For independent systems, the generation variable "GEN" refers to the inverter output for PV and the discharge for storage. For PV+battery hybrid systems, we created new variables to distinguish between (a) energy coming directly from the PV array to the inverter (GEN_PVB_P) and (b) energy being discharged from the battery (GEN_PVB_B). The total generation (GEN) from the PV+battery hybrid is dependent upon these two components.

Table 3. Variables for representing a loosely DC-coupled PV+battery technology in ReEDS

\begin{tabular}{|c|c|c|c|c|}
\hline Variable & $\begin{array}{l}\text { Approaches for } \\
\text { PV+battery }\end{array}$ & $\begin{array}{l}\text { Independent } \\
\text { PV Value }\end{array}$ & $\begin{array}{l}\text { Independent } \\
\text { Battery Value }\end{array}$ & PV+battery Value \\
\hline $\begin{array}{l}\text { Capacity } \\
\text { (CAP) }\end{array}$ & $\begin{array}{l}\text { Tracks array } \\
\text { capacity only; } \\
\text { uses ILR and } \\
\text { BIR to define } \\
\text { the other } \\
\text { components }\end{array}$ & $\begin{array}{l}\mathrm{CAP}=\mathrm{PV} \\
\text { Array Capacity } \\
{[\mathrm{MW} \text { DC }]}\end{array}$ & $\begin{array}{l}\text { CAP = Battery } \\
\text { Capacity } \\
{[\mathrm{MW} \text { DC }]}\end{array}$ & $\begin{array}{l}\mathrm{CAP}=\text { Array Capacity } \\
{[\mathrm{MW} \text { DC }]} \\
\mathrm{CAP}_{\text {Inverter }}=1 / \mathrm{ILR} * \mathrm{CAP} \\
\mathrm{CAP}_{\text {Batt }}=\mathrm{BIR} * \mathrm{CAP} / \mathrm{ILR}\end{array}$ \\
\hline $\begin{array}{l}\text { Generation } \\
\text { (GEN) }\end{array}$ & $\begin{array}{l}\text { Add new } \\
\text { variables that } \\
\text { are linked back } \\
\text { to total GEN }\end{array}$ & $\begin{array}{l}\text { GEN }=\text { PV } \\
\text { Array Output } \\
\text { [MWh AC] }\end{array}$ & $\begin{array}{l}\text { GEN = Battery } \\
\text { Discharge } \\
{[\mathrm{MWh} A \mathrm{C}]}\end{array}$ & $\begin{array}{l}\text { GENPV }=\text { Gen from array } \\
\text { GEN } N_{\text {Batt: Gen from battery }} \\
\text { GEN }=\text { GENPV }+ \text { GEN }_{\text {Batt }} \\
{[\mathrm{MWh} \text { AC }]}\end{array}$ \\
\hline $\begin{array}{l}\text { Storage Charging } \\
\text { (STORAGE_IN) }\end{array}$ & NA & NA & $\begin{array}{l}\text { Battery Charging } \\
{[\mathrm{MWh} \mathrm{AC}]}\end{array}$ & NA \\
\hline $\begin{array}{l}\text { Storage Charging from } \\
\text { the Grid } \\
\text { (STORAGE_IN_PVB_G) }\end{array}$ & $\begin{array}{l}\text { Explicitly track } \\
\text { the energy } \\
\text { charged from } \\
\text { the grid }\end{array}$ & NA & NA & $\begin{array}{l}\text { Energy charged from the } \\
\text { grid } \\
{[\mathrm{MWh} A C]}\end{array}$ \\
\hline $\begin{array}{l}\text { Storage Charing from the } \\
\text { local PV } \\
\text { (STORAGE_IN_PVB_P) }\end{array}$ & $\begin{array}{l}\text { Explicitly track } \\
\text { the energy } \\
\text { charged from } \\
\text { the local PV }\end{array}$ & NA & NA & $\begin{array}{l}\text { Energy charged from the } \\
\text { local PV } \\
\text { [MWh DC] }\end{array}$ \\
\hline $\begin{array}{l}\text { Storage Level } \\
\text { (STORAGE_LEVEL) }\end{array}$ & $\begin{array}{l}\text { Leave } \\
\text { unchanged }\end{array}$ & NA & $\begin{array}{l}\text { Dispatchable battery } \\
\text { energy } \\
{[\mathrm{MWh} A C]}\end{array}$ & Same as independent \\
\hline
\end{tabular}

\footnotetext{
${ }^{26}$ For independent batteries and PV, CAP refers to the battery and PV array capacity, respectively.
} 
For independent systems, the storage charging variable "STORAGE_IN" refers to the energy entering storage. For PV+Battery systems, we created new variables to distinguish between charging from local PV (STORAGE_IN_PVB_P) and charging from the grid (STORAGE_IN_PVB_G).

The remainder of this appendix summarizes the constraints developed and implemented for our loosely DC-coupled PV+battery hybrids. The equation names referenced in this section are taken from the ReEDS model version 2020.

\section{PV Constraints}

The following constraints are specific to the PV component of the hybrid technology, including tracking capital stock, PV technical potential resource limits, and induced operating reserves.

\section{Tracking Capital Stock}

Capital stock is tracked through a suite of constraints, based on plant vintage: initial capacity, new construction, and refurbishments. Initial capacity ("init" vintage set) is that which exists prior in the first historical year modeled in ReEDS. Exogenous trajectories define how much of the initial capacity remains in each model year " $t$ " which is based on an exogenous retirement schedule. (eq_cap_init_noret). For this report, we assume there is no initial hybrid PV+battery capacity in 2010.

\section{Capacity ["init", $t]$ = initial capacity remaining[t]}

New capacity is comprised of new construction and capacity refurbishment (reconstruction of a retired plant at a reduced investment cost). Capacity stock from the "new" vintage set is tracked in each model year " $\mathrm{t}$ " is as the total investments from all prior years that has not reached the end of their economic life, adjusted for degradation effects (eq_cap_new_noret).

Capacity ["new",t] = Undegraded capacity of both new construction and refurbishments that are still in operation

The amount of capacity that may be refurbished in model year " $t$ " is limited by the total amount of capacity from investments that have reached the end of their economic lifetime plus the amount of capacity that has been degraded (eq_refurblim).

Refurbishments $[t]<=$ Retired and degraded capacity of new construction and refurbishment + Retired initial capacity

$\underline{\text { PV resource limit }}$

The deployment of PV capacity is limited by the PV technical potential - estimates of capacity that may be deployed within a given region and resource quality classification after spatial exclusions have been applied (Maclaurin et al. 2019). ReEDS uses a piece-wise linear supply curve that identifies the amount of resource that may be interconnected with the grid and the cost for the interconnection. The supply curve is divided into five cost bins. Capacity investments are tracked by supply curve bin and cannot exceed the available resource of any one bin (eq_rsc_INVlim). 
Investment associated with a supply curve bin cannot exceed the available resource within that bin. In addition, the total capacity investment for all bins must equal the total of new investments (eq_rsc_inv_account).

\section{Total investment from all cost bins $=$ Total PV investments}

Induced operating reserves:

We assume independent PV resources induce operating reserve requirements as a function of the PV capacity during daytime hours (Cole, Eurek, et al. 2018). We apply this same assumption for hybrid PV+battery. Therefore, hybrid PV+battery investments increase the operating reserve requirement in the supply/demand balance constraint for operating reserves

(eq_OpRes_requirement). Additionally, hybrid batteries provide operating reserves (see the section below "Operating reserve supply limit")

\section{Storage Constraints}

The following constraints are specific to the Battery component of the hybrid technology, including storage operations and battery-specific policies.

\section{Storage capacity limit (eq_storage_capacity)}

These constraints limit the use of storage for charging, discharging, and providing operating reserves to be less than the storage capacity. For PV+battery hybrids, the storage capacity is modeled implicitly as the battery-to-inverter ratio multiplied by the PV array capacity and divided by the ILR.

Discharge + Charge + Operating reserves $<=$ battery inverter ratio $*(P V$ array capacity / ILR $)$

Storage level energy balance (eq_storage_level)

These constraints track the dispatchable battery energy ("level") using a daily inventory balance constraint. The dispatchable energy in storage during the next time-slice " $h+1$ " is equal to dispatchable energy in storage in the current time-slice " $h$ " plus energy charged in " $h$ " less energy discharged in " $\mathrm{h}$ ". The storage efficiency is applied to the "Charge" variable to reflect that energy leaving storage will be less than the energy coming into storage due to losses. The energy entering storage from the local PV is already DC and, therefore, has lower losses compared with energy from the gird that must be first converted from $\mathrm{AC}$ to $\mathrm{DC}$.

Energy Level $[h+1]=$ Energy Level $[h]+$ storage efficiency * Energy Charge $[h]-$ Energy Discharge[h]

\section{Storage energy limit (eq_storage_duration)}

These constraints limit the dispatchable storage energy ("level") to be less than the storage energy capacity. The storage capacity is tracked implicitly as the PV array capacity multiplied by the battery-to-inverter ratio and divided by the ILR.

Energy Level <= battery inverter ratio * (Panel DC Capacity / ILR) * storage duration

Operating reserve supply limit (eq_ORcap): 
Generators can contribute towards the supply of operating reserves, limited by the ramp rate of the generator. However, we assume storage is not bound by ramping and can supply operating reserves up to the storage capacity per eq_storage_capacity. The supply/demand balance constraint for operating reserves (eq_OpRes_requirement) includes the storage operating reserve variable (OPRES).

\section{Storage Mandate (eq BatteryMandate):}

We assume PV+battery is eligible to contribute towards state-specific, capacity-based, battery mandates.

Total battery capacity $>=$ battery capacity requirement

Storage Charging: Lower Bound (eq_storage_in_min)

Storage charging that is not used for curtailment recovery must be greater than a minimum amount. We calculate the minimum amount of storge charging based on the simulated hourly operations of storage.

\section{Storage Charging: Upper Bound (eq storage in max)}

We track storage charging by source ("existing" VRE, "new" PV, "new" Wind) to indicate if charging is recovery curtailment from this source. Then we limit the storage recovery based on the amount of curtailment from each source.

Storage Charging ("existing" VRE) $<=$ Estimated curtailment from "existing" VRE

Storage Charging ("new PV") <= Estimated curtailment from "new" Wind

Storage Charging ("new Wind") <= Estimated curtailment from "new" PV

\section{Hybrid Constraints}

The following constraints are derived based on the combined interaction of the PV and Battery components, including, enforcing the battery ITC requirements, detailed operations of the hybrid system, capacity credit, curtailment, and state RPS REC accounting.

\section{ITC charge requirement}

Based on existing statutes and guidance from the U.S. Internal Revenue Service, a battery is eligible for the ITC if at least $75 \%$ of its stored energy (on an annual basis) is sourced from the PV array for the first five years of operation. We do not impose this constraint by default, but it is available in the model for sensitivity analysis (see Appendix C).

\section{Charge from local PV array $>=0.75 *$ (Charge from local PV array + Charge from Grid)}

\section{Inverter capacity limit (eq_pvb_inverter_limit)}

These constraints limit energy sent through the inverter to be less than the inverter capacity in each time slice. The inverter capacity is tracked implicitly as the PV array capacity divided by the inverter loading ratio. 
$P V$ array power output + Storage power discharge + Storage power charge from grid + Operating reserves $<=P V$ array capacity / ILR

\section{Total generation definition (eq_pvb_gen_total)}

We explicitly track the source of energy going through the hybrid plant inverter. This is necessary because the generation variable GEN traditionally refers to post-curtailment output for a generation asset and discharge for a storage asset. Therefore, we employ new variables to distinguish between the two for the hybrid plant. Additionally, constraints enforce the generation from the hybrid plant to be the sum of energy coming directly from the PV array and energy being discharged from storage minus storage charged from the local PV array.

Generation from hybrid PV array + Generation from hybrid storage - Storage charge from local $P V$ array= Generation from the hybrid plant.

\section{PV array energy limit (eq_pvb_array_energy_limit)}

These constraints require the sum of energy charged into storage during daytime hours that is not used for curtailment recovery-i.e., STORAGE_IN_PVB_P(“other") — and energy sent to the grid directly from the PV array must not exceed the energy produced from the PV array. The use of the inequality allows for dumping of energy due to low voltage events and clipping.

Note: The PV array DC capacity factors values are approximated by adjusting the AC capacity factors for independent to account for clipping and low voltage energy that could be recovered by storage. Therefore, these approximate DC capacity factors already include the inverter losses.

Charge from $P V$ array (excluding curtailment recovery) + Generation from array (post curtailment $)<=D C$ capacity factor * array DC capacity

\section{Planning Reserve Margin (eq_reserve_margin)}

The sum of capacity available in a region must meet the peak demand plus a reserve margin. Independent $\mathrm{PV}$ is credited between zero and 100 percent of nameplate capacity based on contributions of PV output to net peak load hours (B. A. Frew et al. 2017). Independent batteries are credited using hourly chronological methods described by (Frazier et al. 2020). The capacity credit of PV+battery hybrids is calculated using the same methods as the independent PV and battery technologies, but the total capacity credit of the hybrid is limited to 1.0.

\section{Curtailment}

There are two constraints used to track and enforce curtailment:

1. Curtailment definition (eq_curtailment) - Total curtailment is calculated by balancing area and time-slice, including curtailment for existing capacity and new investments, curtailment induced by must run generation, curtailment reduced through transmission and curtailment recovered through storage. Curtailment recovery is estimated as a fraction of energy charged in storage during a time-slice.

Curtailment $=$ required curtailment (existing VRE, new VRE, must run generation) curtailment reduction through transmission - curtailment recovery through storage

2. Curtailment settlement (eq_curt_gen_balance) - This constraint requires curtailment settlement for all VRE resources within a region: Energy sent to the grid plus operating 
reserves cannot exceed total energy produced from curtailable resources minus the required curtailment. This constraint ensures the VRE generation (GEN) represents output after curtailment has been removed.

\section{Generation (post curtailment) + Operating Reserves $<=$ Resource - Curtailment}

We assume the hybrid battery must only charge from local PV during the daytime hours when the sun is shining; therefore, the hybrid battery is limited to recovering curtailment from the local PV based on the PV energy that is expected to be curtailed from the hybrid plant (eq_storage_in_max).

We calculate how much curtailment from new PV can be recovered by adding storage. For example, if the curtailment recovery value is $50 \%$, then only half of the curtailment can be recovered by storage regardless of how much you use the storage.

\section{State RPS Renewable Energy Certificates (RECs) (eq_REC_Generation)}

We wish to track only primary sources of renewable energy. Because a bi-directional hybrid battery can charge from the grid, we must ensure not to count grid energy that has already been counted for RPS RECs. Therefore, we add a hybrid-specific constraint for tracking RECs for PV +battery to be equal to post-curtailment generation from the hybrid PV plus total discharge from storage minus charging from the grid.

Hybrid RECs $<=$ Generation from local PV + Discharge from Storage - Charge from Grid 


\section{Appendix B. Supporting Solar Resource Analysis}

To estimate the potential for additional energy production from a DC-coupled PV+battery hybrid, we estimate the clipped energy that could be recovered by a DC-coupled battery in systems with a PV ILR of 1.3 (Figure 5). This calculation utilizes data assembled by NREL's Renewable Energy Potential (reV) model, which couples hourly weather data from the National Solar Radiation Database (NSRDB) with the System Advisor Model (SAM, using assumptions taken from PVWatts version 7) to generate hourly simulations of PV DC and AC generation across the conterminous United States. The reV model includes detailed data on land areas expected to be excluded from utility-scale PV deployment, such as water bodies, high-groundslope areas, urban areas, parks, and areas of environmental concern. In Figure 5, the underlying $90 \mathrm{~m}$-resolution reV data are aggregated into $\sim 55,00011.5 \mathrm{~km} \times 11.5 \mathrm{~km}$ grid cells, and a PV system with horizontal 1-axis tracking is simulated at each cell with non-zero developable area. Completely excluded cells are shown in gray.

The energy lost to clipping is given by the pre-inverter DC output minus the inverter nameplate capacity during hours when the inverter output is saturated. It is reported here as a fraction of the total available pre-inverter DC output from PV averaged over 2007-2013. As we are interested in the energy that could be recovered by a DC-coupled battery, the clipped energy is not multiplied by the inverter efficiency; to determine the energy that could be recovered by sizing the inverter to completely avoid clipping, the clipped energy reported here would be multiplied by the assumed inverter efficiency of $96 \%$. The maximum recoverable clipped energy for ILR $=1.3$ is $\sim 2.1 \%$ of total DC energy, observed at a small selection of sites in the southwest. The average recoverable clipped energy is $0.2 \%$. Larger amounts of clipped energy would be available at higher ILRs. 


\section{Appendix C. ITC Qualification Sensitivities for the Battery Component}

In Section 4.3, we compare the rate and ultimate level of PV+battery deployment under scenarios in which the battery component of the hybrid receives no $(0 \%)$ or partial $(75 \%)$ ITC benefit. Per the relevant legislation and guidance from the U.S. Internal Revenue Service, the battery component of the hybrid qualifies for ITC benefit if at least $75 \%$ of its stored energy is derived from the local PV for the first five years of operation. This requirement is difficult to represent in the ReEDS investment decision framework due to the model structure, so we chose to exclude charging requirement in the core scenarios presented in Section 4.3. Here, we examine the impacts of this charging requirement by varying the minimum share of stored energy that must be derived from local PV relative to the total amount of energy charged (local PV + grid), including $0 \%, 25 \%, 50 \%$ and $75 \% .{ }^{27}$ This constraint is applied for the full operational lifetime of the hybrid system, which is more stringent than what is prescribed in the legislation and Internal Revenue Service guidance. We assume that the hybrid batteries receive full arbitrage value regardless of the charging requirement, but the arbitrage value will be dependent upon the amount of grid charging.

As shown in Figure 15, the total PV+battery capacity in 2050 is largely insensitive to the charging requirement constraint: across all scenarios, approximately $200 \mathrm{GW}$ of UPV capacity adopts the hybrid configuration. Minor changes are observed for the independent UPV and battery technologies, which indicates that the hybrid operational constraints have a modest effect on the value of its independent counterparts.
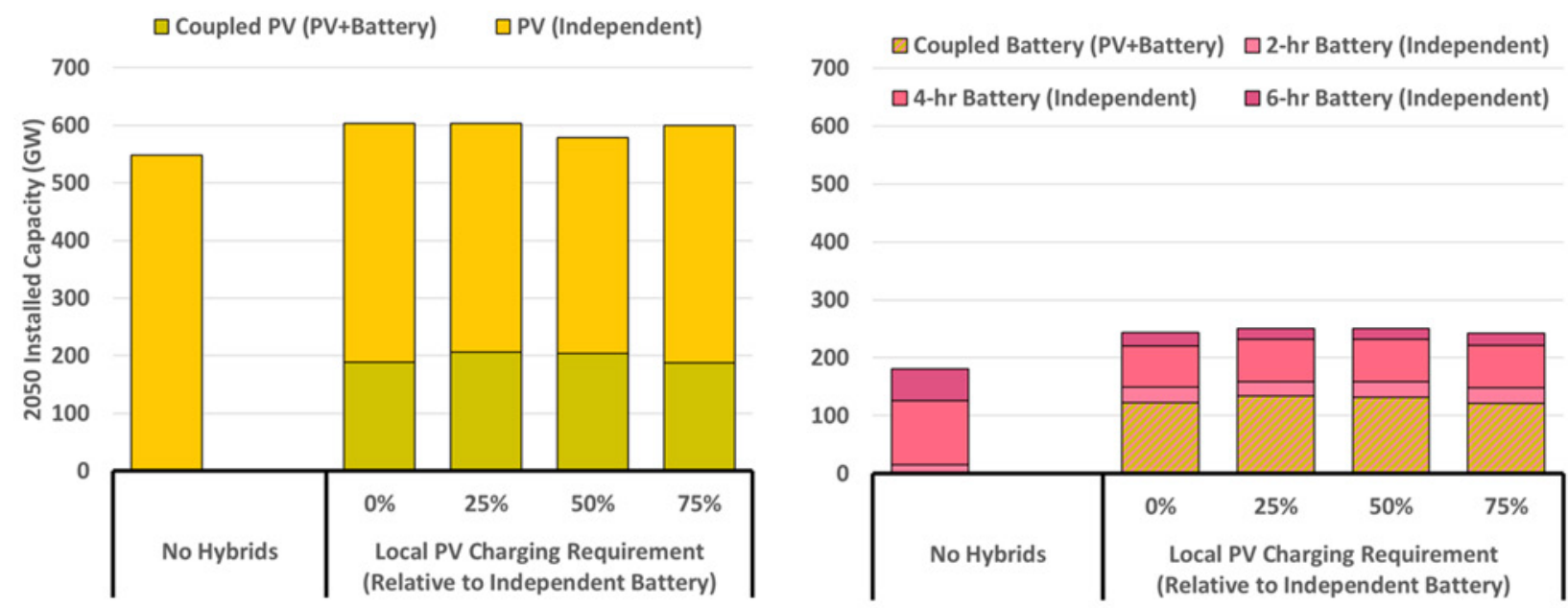

Figure 15. Installed UPV (left) and battery (right) capacity by 2050 for hybrid and independent systems across sensitivities related to the ITC charging requirement.

Despite the similar overall hybrid deployment, the operational constraints have implications for the battery component's operational behavior. Figure 16 shows the share of PV+battery systems

\footnotetext{
${ }^{27}$ These scenarios all include an ITC benefit for the battery component of the hybrid, so the $0 \%$ scenario in the appendix differs from the Reference case.
} 
that qualify for the battery ITC based on operations in the year when the system is first built. If the charging requirement is below $75 \%(0 \%, 25 \%, 50 \%)$, the majority of $\mathrm{PV}+$ battery systems charge less than $75 \%$ of their energy from the local PV, but $\sim 30 \%$ of PV+battery plants do operate in a way that is consistent with the battery component's partial qualification for the ITC. This result is consistent (and unchanged) from those presented in Section 4.3. The fact that most hybrid systems perform below the $75 \%$ qualification standard reflects preference for the hybrid systems to be able to charge more than $25 \%$ of their energy from grid.

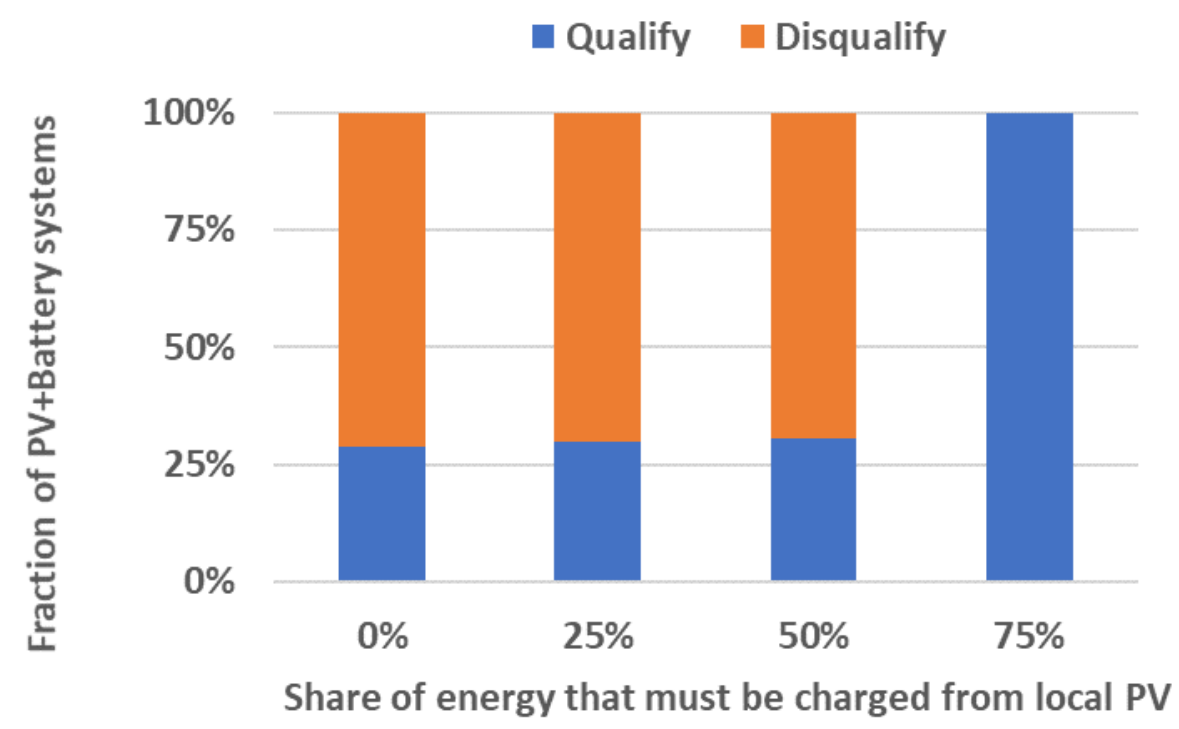

Figure 16. Share of PV+battery systems whose battery components qualify for the partial ITC
value $(75 \%)$, based on the first year of operation.

"Disqualify" indicates that less than $75 \%$ of the energy stored by the battery component in the first year of a $\mathrm{PV}+$ battery hybrid's operations is derived from the local PV.

\begin{abstract}
"Qualify" indicates that at least $75 \%$ of the energy stored by the battery component in the first year of a PV+battery hybrid's operations is derived from the local PV. The blue bars present in the $0 \%, 25 \%$, and $50 \%$ charging constraint scenarios indicate the share of PV+battery hybrids that choose to operate in a way that is consistent with ITC qualification, without being forced to do so. The $75 \%$ bar is solid blue because such operational behavior is required by model constraints in that scenario.
\end{abstract}

In conclusion, the results of these additional tests indicate that PV+battery deployment and operations are largely insensitive to charging constraints that fall below the minimum charging requirement for the battery component's ITC qualification. Moreover, they indicate that our default PV+battery hybrid configuration is unlikely to operate in a way that is consistent with partial ITC qualification for the battery component, unless forced to do those. This result supports our assumption about the battery component not qualifying for the ITC in our default PV+battery configuration is appropriate. However, the appropriateness of this assumption will likely be a function of battery size, since an alternative configuration with a smaller battery (in terms of its energy and power capacities) may be more likely to derive a larger share of its stored energy from local PV. 


\section{Appendix D. Hourly Arbitrage Value Sensitivities}

In Section 4, we examine scenarios in which PV+battery hybrids are able to capture the full hourly arbitrage value associated with charging from (and later discharging to) the grid. However, the battery component of a PV+battery hybrid may not be able to realize this full arbitrage value, due to limitations imposed by the shared inverter. In other words, if PV generation being sent to the grid saturates the total inverter capacity in a given hour, then the battery component will not be able to either charge or discharge to enable hourly arbitrage value.

Here, we explore the impacts of derating the hourly arbitrage value of the hybrid's battery component, such that the PV+battery hybrid can only realize $80 \%$ or $90 \%$ of the hourly arbitrage value that an independent battery can generate. These derates are layered with Reference scenario assumptions for all other inputs (e.g., $-5 \%$ cost savings), and they are meant to serve as a proxy for the times during which inverter capacity is unavailable. The arbitrage value calculation for independent batteries is performed between solve steps, based on hourly price profiles and battery characteristics. The resulting hourly arbitrage value is then decremented by $10 \%$ or $20 \%$ for the hybrid configuration in these scenarios and ultimately compared against our default assumptions (of 100\% hourly arbitrage value for the hybrid configuration).

Figure 17 shows that the deployment of PV+battery hybrids is reduced by half when the hourly arbitrage value is derated by $20 \%$ (i.e., the $80 \%$ arbitrage value results). This effect is roughly equivalent to removing the assumption of cost savings associated with hybridization (i.e., the difference between our Reference scenario and a sensitivity in which PV+battery costs are equal to the sum of costs for independent PV and battery systems). Therefore, we find that PV+battery deployment in ReEDS is highly sensitive to the hourly arbitrage value of the battery component for the configuration examined in this study.
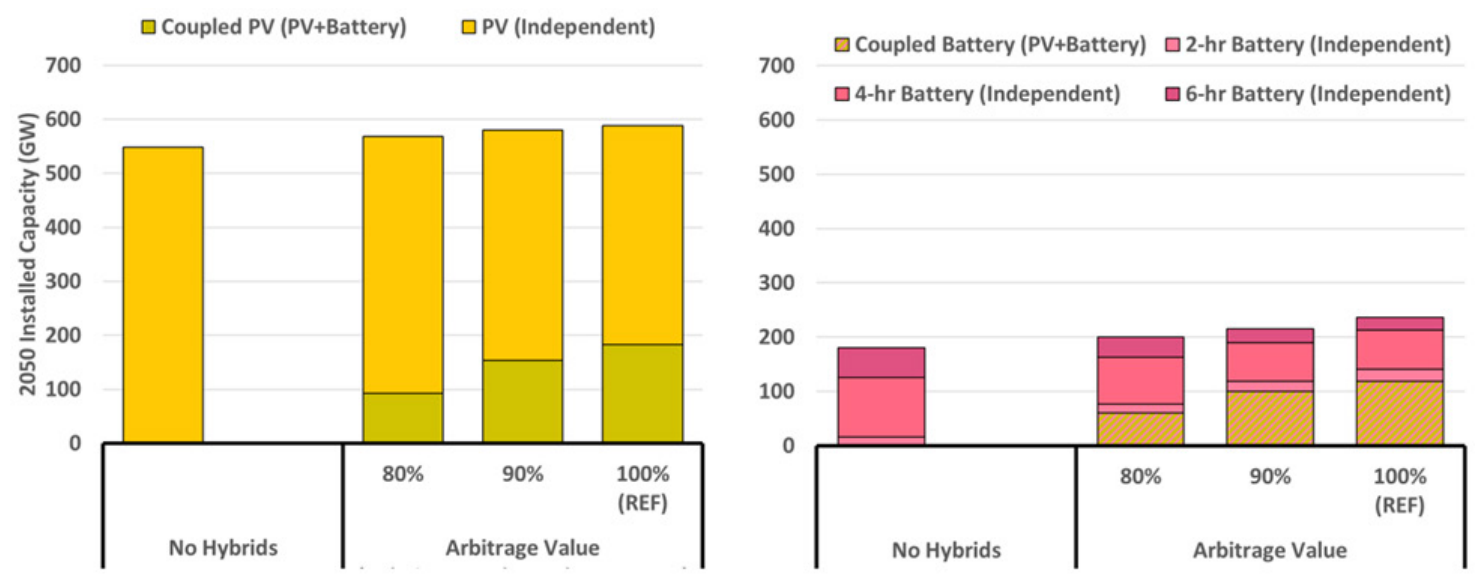

Figure 17. Installed UPV (left) and battery (right) capacity in $\mathbf{2 0 5 0}$ for hybrid and independent systems across sensitivities related the hourly energy arbitrage value.

Because the arbitrage opportunities are linked to grid charging, additional work is required to better understand how this value may be impacted by hybrid systems whose battery component qualifies for the ITC (Appendix C). Planned future work will also explicitly derate hourly arbitrage value based on the times during which inverter capacity is not available for arbitrage operations (based on grid charging). 